\title{
SEISMIC DESIGN OF
}

\section{PUBLIC BUILDINGS}

R. B. Shephard* and O. A. Glogaut

\section{Synopsis}

This paper is in two sections.

The senior author discusses in the first section the reasons for some of the revised provisions in the current Ministry of Works, Structural Design office, Code of Practice for the design of buildings, while the junior author deals in the second part with the application of these provisions to a reinforced concrete shear core building. He presents methods of designing and detailing a core for ductility and the effect of incremental damage to the spandrels in a coupled shear wall are examined.

\section{SECTION A}

Some notes on the Revised Ministry of Works code of Practice for The Deign of Public Buildings.

\subsection{Introduction}

Code making in N.Z. is largely a voluntary effort from people with full time jobs. Not surprisingly it takes a long time to produce a code. A recent example is the proposed revision of N.Z.S.S. 1900 Chapter 9.3, Concrete which is essentially an adaptation of the 1963 ACI code for use in a seismic area. It is not yet available. It is not the purpose of this paper to discuss code making nor does the author wish to be unduly critical; the above example is merely cited as one reason why it is necessary for a progressive organisation like the M.O.W. to supplement the current N.Z. Model Building Bylaws by a code of practice of their own that allows its designers to avail themselves of the most up to date information and methods.

The Ministry of Works, Structural Design Office, Code of Practice for the design of Public Buildings, has as its principal objective aseismic design. The relevant N.Z. Model Building Bylaw is mainly concerned with the prevention of panic amongst, or injury and loss of life to, persons in and around buildings during earthquakes. It sets only minimum standards. The M.O.W. must in addition protect the interests of the N.Z. Government as the owner of Public Buildings, the provider of subsidies and loans for many building projects, and the Insurer of all buildings against earthquake damage. From this aspect the following two additional objectives are derived:

(a) To prevent material damage to buildings and to stop buildings from inflicting damage to adjacent buildings during moderate earthquakes.

(b) To assure ease of restoration, strengthening or replacement if damage occurs.

\footnotetext{
* Senior Engineer

+Chief Structural Engineer, Ministry of Works, wellington
} 
The code gives the minimum requirements to achieve these objectives while taking into consideration the function, appearance, cost and ease of erection of buildings.

In 1968 our code of practice was extensively revised. The more significant variations from our 1966 edition are discussed in the following.

\subsection{General Provisions}

\subsection{Slender Horizontal Diaphragms in Shear Wall Buildings}

In buildings of this type a dual approach is recommended.

(a) A distribution of the total lateral force in accordance with relative stiffnesses considering interaction of frames and shear walls. It is frequently found that this approach taxes columns of the upper stories most heavily due to stresses induced by shear wall deformation.

(b) A minimum lateral force to be applied to the frames considering the shear walls to be ineffective. This approach makes the greatest demand on the lower storey columns.

The combined effect of approach (a) and (b) has sometimes resulted in a uniform column detail over its full height - very convenient from a construction point of view.

\subsection{Concrete Quality}

The recommended nominal 28 day concrete strength for all buildings of over $65 \mathrm{ft}$ in height is $4,000 \mathrm{p.s.i}$. The aim is to achieve a more workable concrete for the congested regions of confined members in ductile moment resisting frames and shear walls, to reduce inter-storey deflections, and to resist greater compression, bond and shear stresses under high seismic loads.

\subsection{Height Limits}

Height limits have been raised or entirely removed.

For buildings where an accepted elastoplastic analysis has been carried out using earthquake spectra appropriate for the site there is no height limit.

For shear wall buildings detailed for ductility and buildings with ductile moment resisting frames but which are not analysed as described above, the height limit is from $220 \mathrm{ft}$ to $280 \mathrm{ft}$ depending on the seismic zone.

Buildings not detailed for ductility are limited to one storey with light roof. For buildings from two to four storeys there are provisions for detailing to what is termed 'limited ductility'. These are discussed later.

Reinforced Masonry Buildings can now be constructed up to five stories high in zone $\mathrm{C}$ provided certain conditions with regard to detail- 
ing, construction methods and supervision are met, and where the grouted masonry stresses are low.

\subsection{Design Methods and Energy Dissipation}

The Ultimate strength Design method is recommended for all materials, but should be supplemented by the Working strength method to check service load adequacy.

The Ultimate strength Design method provides for the same load factor equations as recommended currently for reinforced concrete but with an additional factor, $K$, designated "energy dissipation factor", introduced to modify the seismic load, e.g.

$$
\begin{aligned}
& U=1.25(D+L p)+1.25 K \cdot E \cdot \quad \text { or } \\
& U=0.9(D+L p)+1.25 K \cdot E .
\end{aligned}
$$

where $D=$ Dead Load, $I_{p}=$ probable Live Load, $E_{1}=$ Earthquake Load.

Energy dissipation factors and under capacity factors are given for reinforced concrete and structural steel. These factors are considered to be adequate where members are detailed so as to retain their structural integrity after at least 8 reversals when yielding under high seismic loadings in a manner that will provide an overall ductility factor of at least 4 for the building. The suggested energy dissipation factor for reinforced concrete is one and for structural steel 0.85 . For other materials such as prestressed concrete and reinforced masonry, energy dissipation factors will be recommended when more factual information is available.

Material or member under capacity factors are also given. For reinforced concrete these are identical to those given in the draft New Zealand Code. For shop jointed structural steel the under capacity factors are arranged to give the same factor of safety when using ultimate loads and plastic section moduli as when using working stress design under seismic loads. This factor is a maximum of 0.9 and varies downwards with fabrication method etc.

\subsection{Ductility Provisions for Reinforced Concrete}

These are generally the same as those in the draft of the commentary on the New Zealand Code (i.e. the S.E.A.O.C. recommendations for lateral forces 1968) but a less pessimistic view if taken of shear core ductility. Figure 1 compares the potential performance of a shear core with that of a rectangular shear wall. It is seen that for a given maximum concrete strain, much greater inelastic strains in the reinforcement of shear cores can be achieved. The conditions at the sides of large openings are, however, much less favourable and confinement of the concrete in these areas may be required or ribs added (dotted lines in Fig. 1).

The most convenient manner in which concrete can be confined in these positions seems to be by means of lapped stirrups across the shear wall tying the considerable quantities of vertical and horizontal reinforcement which are already present to resist flexural and shear forces. 
It is thought that the cross links need provide no more than half (and probably less) the resistance of the confining steel required at the faces of a section. The reason is that they are not subjected to bending, but only to tensile stresses owing to the balance of concrete pressures perpendicular to their axis. It is important to remember however, that each cross link carries the load component produced by two adjacent compressed columns of concrete. (Figure 2).

Excepting in the lower regions of high shear walls the thickness of the wall is inadequate to allow the cross stirrups to be spliced to normal code lap lengths but the presence of high pressures exerted perpendicular to the splice should make shorter splice lengths effective. It is hoped that tests will be carried out to confirm the above assumptions.

\subsection{Limited Ductility Requirements for Low Concrete Buildings}

The M.O.W. code, as mentioned earlier, makes provision for ductile detailing of all buildings of height greater than one storey with light roof. While this seems to be a reaonsable requirement it must be recognised that the ductility demand on low buildings will in general be less than that on high buildings. In a multi-storey building it is not practical to achieve simultaneous energy dissipation by all the joints of all stories. Additional demands are thus made on those joints that dissipate energy and hence requiring local ductility factors that are significantly higher than that for the building as a whole. If, for example, in a 20 storey building, five stories are effective at a given instance, the required ratio of local ductility factor to overall ductility factor for the building will be much greater than for a two storey building in which one storey is ineffective. Another reason for a lower ductility demand in many small buildings is that member sizes are often governed by non structural considerations and are stronger than required, hence there is a built in reserve. To cope with this type of structure, limited ductility requirements for buildings from two to four stories (depending on seismic zone and type of occupancy) have been developed*. Briefly the provisions allow the columns, if carrying light axial loads and shears, to be stirruped as for beams (excepting the bottom end of the lowest storey which must be fully confined). Special joint reinforcement is not required provided the beam and column depth ratio does not exceed $11 / 3$ (a reasonable and practical ratio) and provided the beam reinforcement is anchored in the column in a manner that will allow the transfer of the concentrated beam reinforcement force by a rational compression mechanism. An acceptable means of anchoring this in an exterior column is by:

(a) Giving the beam reinforcement full anchorage length beyond the $90^{\circ}$ downward bend near the far column face or alternatively

(b) Forming the beam top and bottom rods into a $U$ continuous through the column and extending to the region of the far face.

It is considered necessary, even for these low buildings, to develop ductility in the beams and not the columns. It can be shown that for a member joint ductility factor as low as 2, (expressed in terms of member

*The reasoning is described in Bulletin Vol.2. No.3 September 1969 
deflection) strain ratios $\varnothing u / \varnothing *$ of 5 are required. For ductility factors of 4 the strain ratio goes up to 13. It can be further shown that a symetrically reinforced unconfined section, $\left(f_{\mathrm{y}}=40 \mathrm{ksi}, \mathrm{f}_{\mathrm{c}}=3 \mathrm{ksi}, 2\right.$ to 5\% reinforcement and a useful limit of concrete strain of 0.004 ) subjected to an average axial stress of as little as $0.12 f^{\prime}$, cannot develop strain ratios greater than 6 to 7. Even when a column carries no significant axial stress, strain ratios greater than about 9 cannot be obtained. Since the local ductility factor must be greater than the required overall building ductility factor, the danger of a column yielding mechanism even in a low building is obvious.

\subsection{Shear Stresses in Shear Walls}

Figure 3 shows the effect of the new S.E.A.O.C. provisions. These shear Iimitations have been proposed by the P.C.A. and are based on the behaviour of deep beams. For short deep beams (H/D $=1$ or less) the shear capacity is based solely on the shear capacity of concrete. For longer beams (H/D greater than 2.7) the formula for shear capacity becomes essentially the same as that prescribed by A.C.I. 318-63. For intermediate span-depth ratios straight line interpolations are specified.

$\mathrm{H}$ is defined as the total height to which a shear wall extends in the structure, and $D$ is the width of the wall. If large holes are present the engineer should select the appropriate $H / D$ factor to describe the action of the wall or elements involved. The decision would be based on whether or not deep beam action is involved.

For a wall with openings such that the piers and/or spandrels between are long flexural members, the shear capacity of these members would be determined on this basis, even though $H / D$ of the overall wall may be less than 1. If the wall has a large percentage of openings and the piers and/or spandrels have H/D less than 2.7, the shear capacity would be based on this criteria, even though $H / D$ of the overall wall may be greater than 2.7. This does not imply that a small opening in a tall slender wall will cause the resulting piers on either side of the opening to be considered short, deep beams. The important consideration would be whether or not the openings materially alter the flexural and shear stress distributions in the wall. Similar considerations will be required in other cases. If the critical level is near the top of a wall, the appropriate value of height to use in the equations would be from that level to the top of the wall, rather than the overall height of the wall.

Because of the rapid deterioration of the concrete in short spandrels when subjected to high reversing loads, we tend to assume that the concrete takes no shear in these locations.

In cases where the proportions of spandrels of shear walls do not comply with the minimum width to height ratio of 0.4 recommended by the S.E.A.O.C. for ductile moment resisting frames, we confine the concrete by means of cross ties between flexural or shear reinforcement.

\subsection{Structural Steel}

Structural steel is used to a limited extent in multistorey buildings by the M.O.W. since it is an imported material. The 1968 S.E.A.O.C. provision for Steel Ductile Moment-Resisting Space Frames are recommended.

*For symbols refer to "Design of Multistorey Buildings"

Blume, Newmark and Corning. 


\subsection{Reinforced Masonry (R.M.)}

\subsection{Height Limits}

These have been raised compared with our previous code of Practice. But in view of the fact that, compared with reinforced concrete, reinforced masonry is far more difficult to reinforce in a manner that may achieve ductile behaviour, in that it is less homogenous, and more difficult to construct and supervise, it is considered reasonable to retain height limits. Depending on seismic zone $R . M$. buildings up to five stories high are allowed plus an additional two bottom stories in reinforced concrete.

\subsection{Stresses}

In recognition of the poor earthquake performance of shear walls not reinforced for ductility (ductile detailing is hardly practical in reinforced masonry) added precautions are taken for buildings over three to four stories. These include increased earthquake loading, together with relatively low allowable stresses for shear, bond, and flexural compression at the boundaries of openings and flanges of shear walls. For deep members the allowable shear stresses are further reduced. Some protection against non-ductile failure is thus achieved. This provision is in the spirit of the S.E.A.O.C. requirements for R.C. shear walls.

\subsection{Spandrels}

The statements of the previous paragraph apply even more to spandrels in coupled shear walls. Tests carried out by Dr. T. Paulay at the University of Canterbury indicate that spandrels deteriorate rapidly under reversing loads. Since it is not practical to use closed stirrups in R.M. spandrels it is advisable to avoid spandrels wherever possible. Cantilevered walls linked by slabs only may be expected to perform better.

\subsection{Lack of Data}

If there are large gaps in our knowledge of R.C. shear wall behaviour this is even more true of R.M. What is the useful limiting strain of the material? The frequently weak bond between the shells of the units and the grout is a matter of concern.

For the above given reasons designers may well consider the use of R.C. as the flange material in R.M. shear walls of higher buildings. This will allow better reinforcement detailing in the regions subjected to high compressive strains.

\subsection{Construction and Testing}

Difficulties in construction and supervision have been mentioned earlier and we are concentrating our efforts towards improvements in this field. To this end two new types of concrete masonry units to Ministry of Works specification have been introduced in this country by the industry (figures 4 and 5). Core tests are taken on all important jobs. 


\subsection{Reinforceable Brick}

The almost complete prohibition of unreinforced masonry for Government financed buildings has encouraged the brick industry to develop extruded hollow units that are reinforceable in a manner similar to hollow concrete units. (figure 5)

\subsection{Veneers}

Conventional unreinforced masonry veneers have had a poor seismic performance record. Height limits are retained for conventional veneers containing a cavity between the structural wall and the veneer or where veneers are attached to timber frames. The Ministry requires close tie spacings and stiff, well anchored ties. Figure 6 shows an improved veneer tie. By turning the ends of the ties up rather than down, as is current practice, good anchorage in the grout of the veneer and structural wall is easier to obtain. This is particularly so where construction of the shell of a structural reinforced hollow masonry wall precedes that of the veneer and ties are in position when the veneer is laid.

If veneers are to be used in seismic zones $A$ and $B$ in buildings exceeding one storey, or two stories in Zone $C$, additional precautions are required such as vertically reinforcing the veneer with galvanised bars in addition to tying it. Alternatively the air space is to be eliminated and the details given in Figure 7 used. Veneers of this type can only move away from the structural wall and are restrained from doing so as shown. It should always be a consideration in the case of a veneer that seismic damage to the structural backing wall should not result in the loss of the veneer from its face. That can only be prevented by the use of close ties and reinforcement.

\subsection{Design Trends}

At present we are endeavouring to obtain more realistic aseismic designs by collaborating with the University of Canterbury in fostering the use of elastoplastic analyses.

With regard to three dimensional coupled shear walls we are working with Ministry of Works, Central Laboratory, in checking computer results by means of model tests. Figure 8 shows a $1: 30$ model cast in epoxy resins. The sides of openings are protected by substantial vertical ribs running the full height of the shear core. The presence of these ribs also allows widening of the spandrels over the openings thus improving their depth to width ratio and increasing the available shear resisting cross section. 


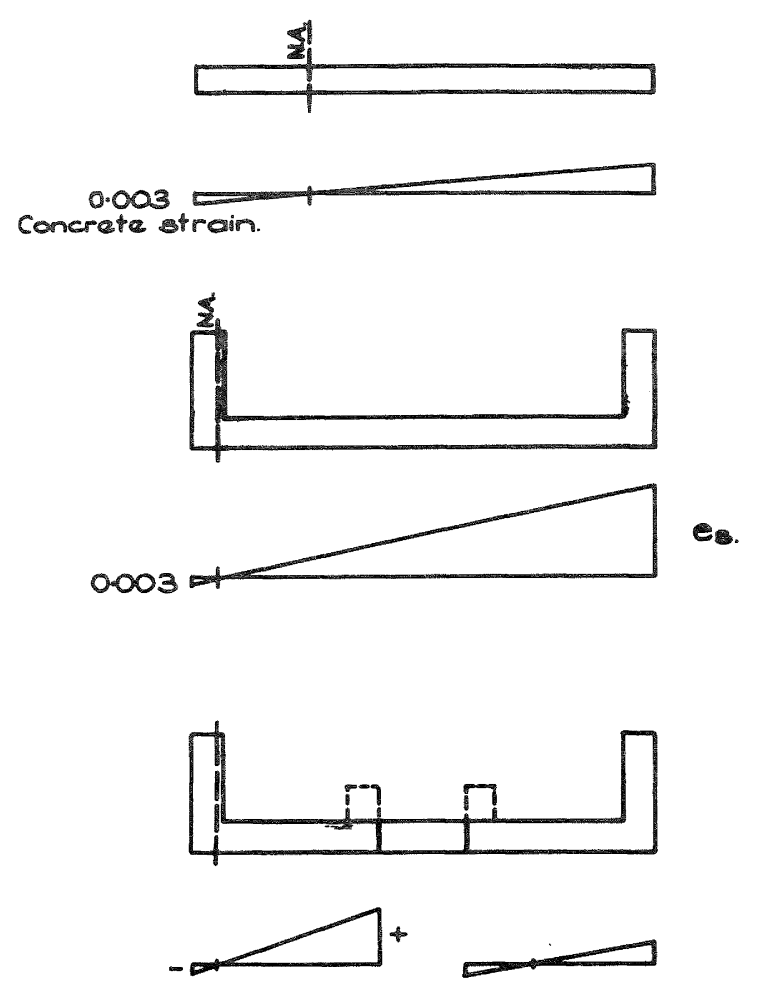

DUCTILITY OF SHEAR WALLS.

Fig 1.

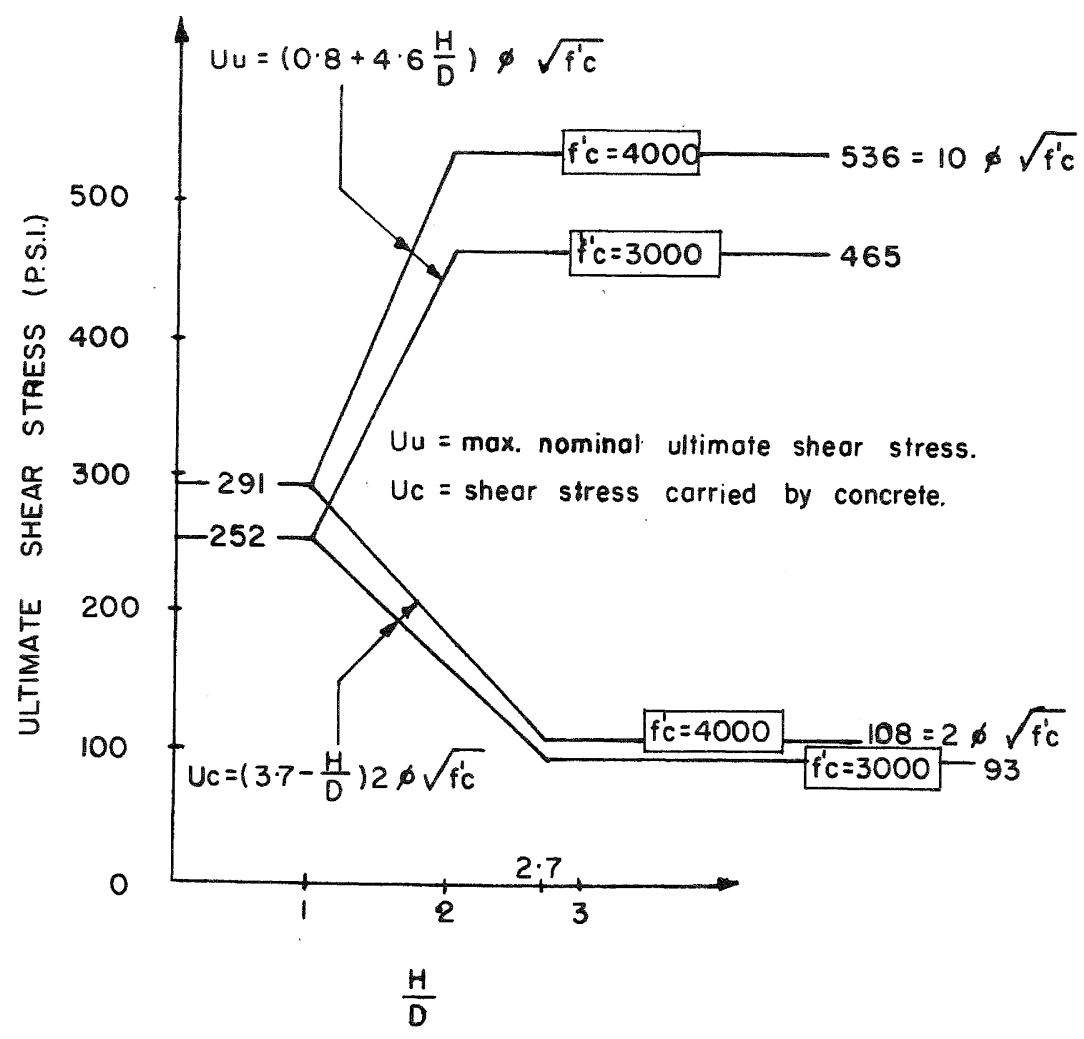

SHEAR STRESS IN SHEAR WALLS.

Fig 3

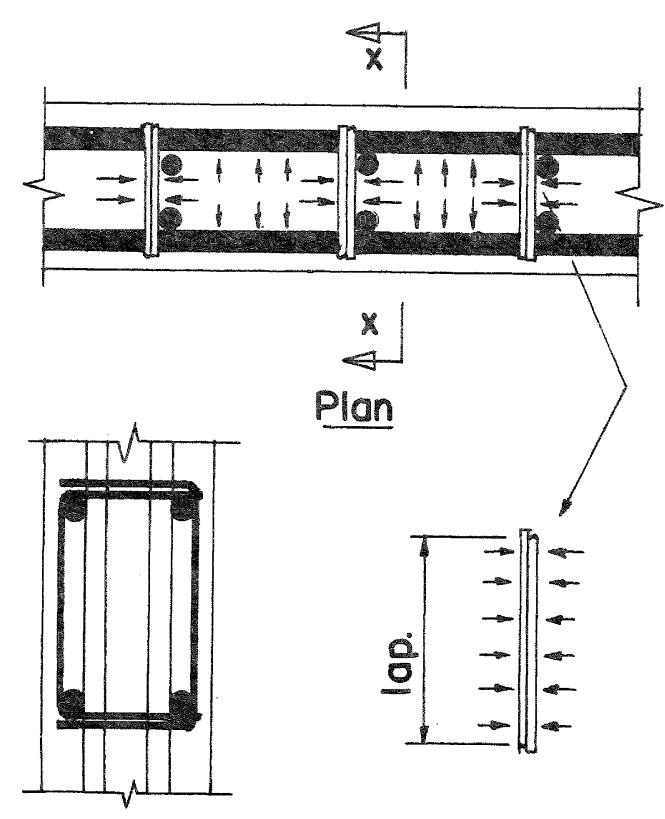

$$
\underline{x-x}
$$

CONFINING TIES IN SHEAR WALLS

Fig 2

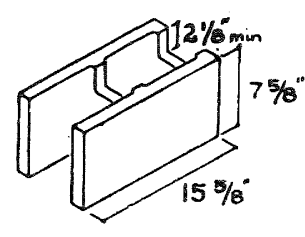

OPEN ENO BOND BEAM

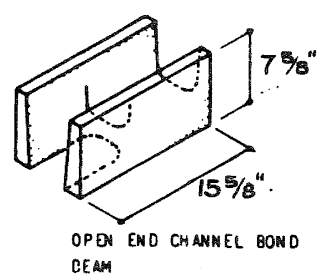

Fig 4 


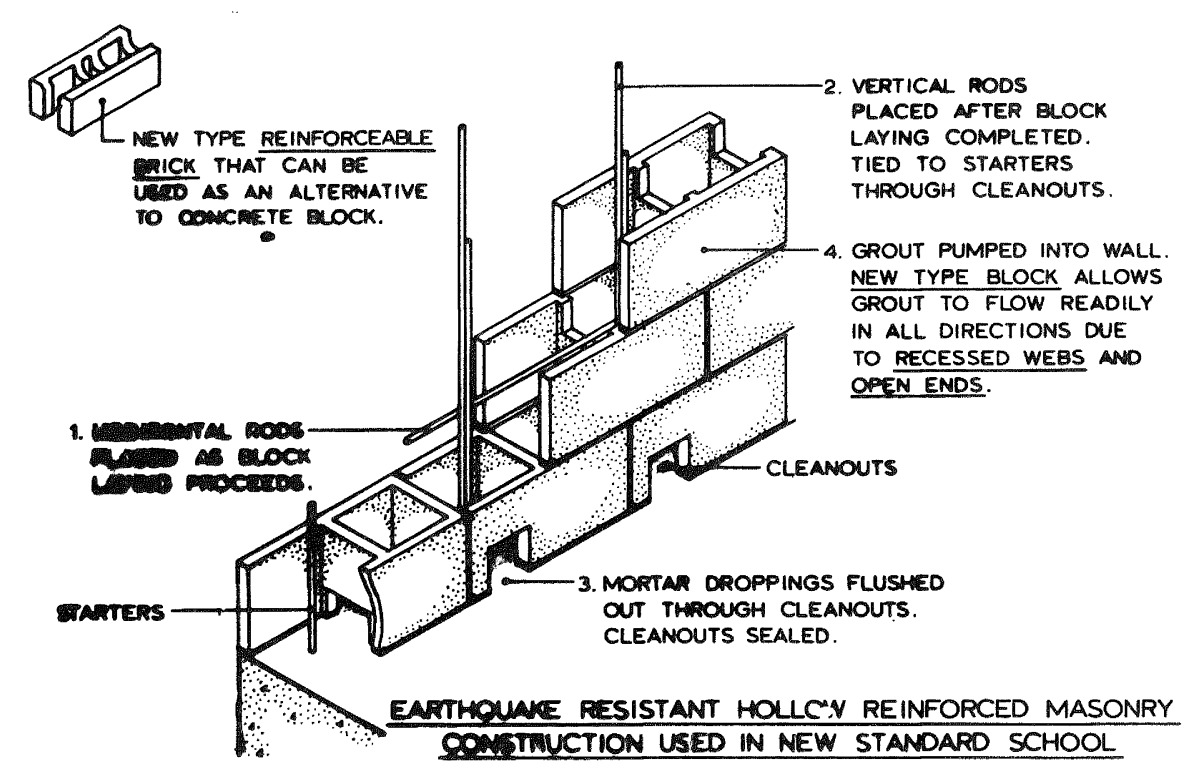

Fig 5
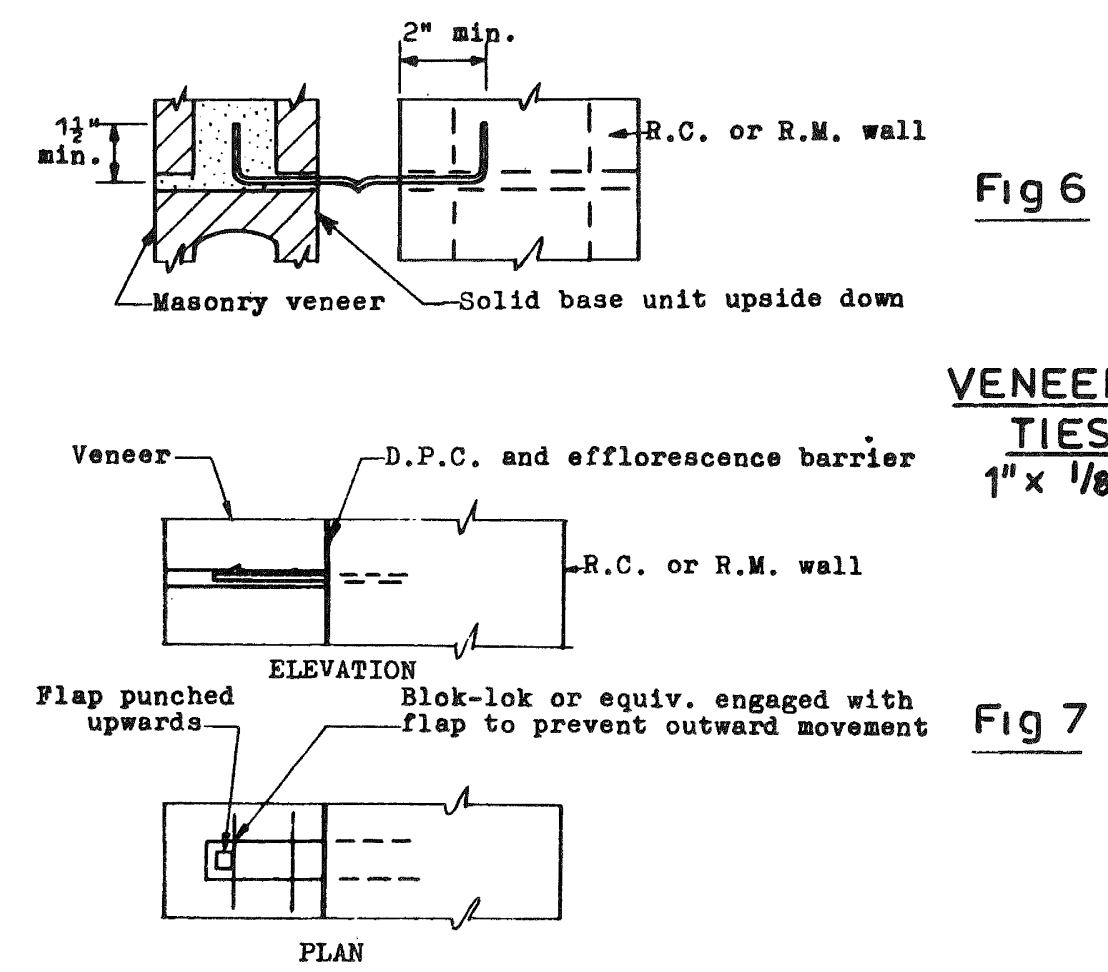

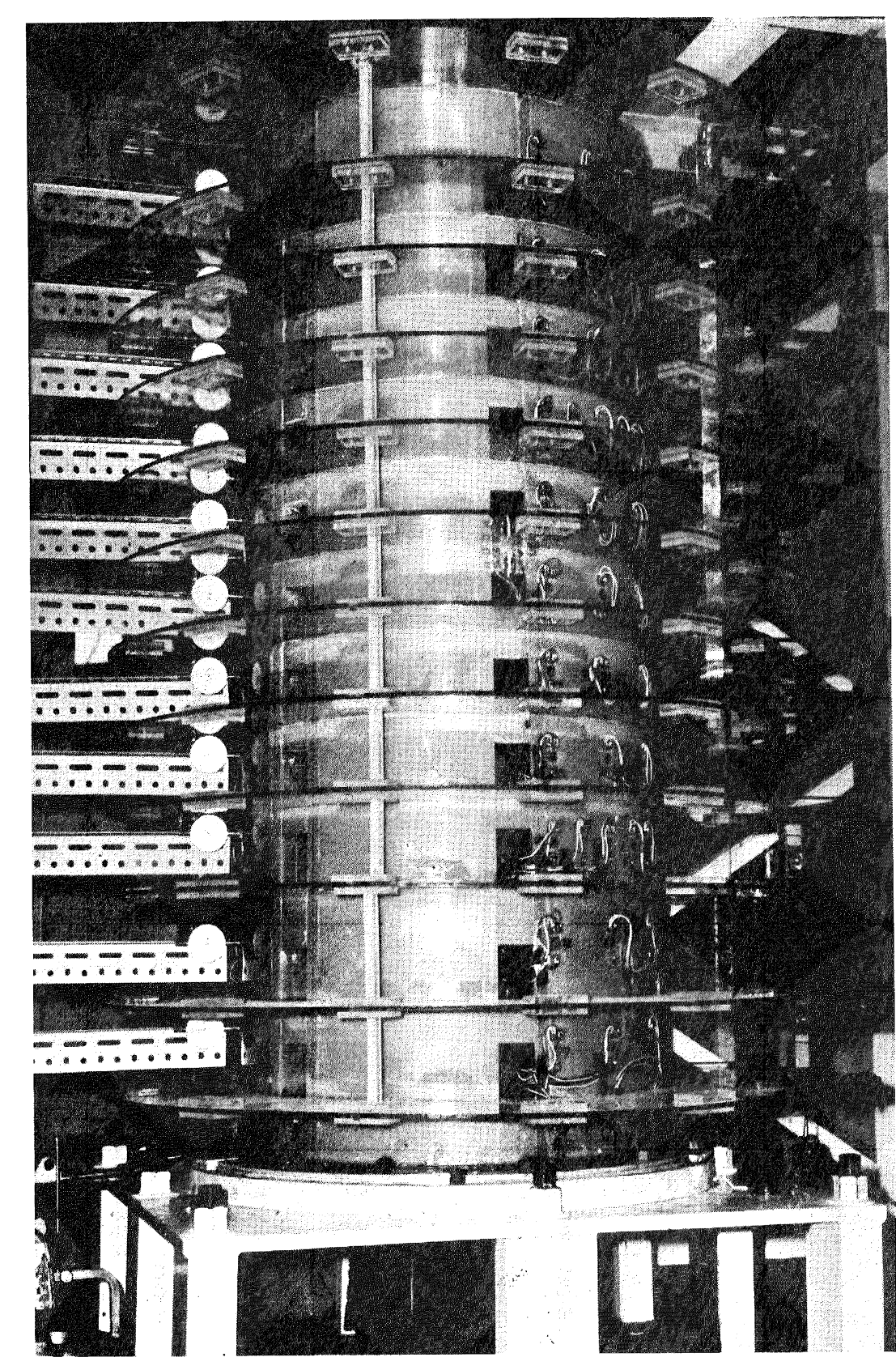

1:30 CAST EPOXY PROTOTYPE SHEAR CORE FOR PROPOSED PARLIAMENT BUILDINGS Fig 8 
Section B

Design of a Multistorey Reinforced Concrete Shear Core Building to Resist Seismic Loadings.

\section{Introduction}

Reinforced concrete seismic design is extended to cover the theory, and more particularly the practical details, for the design of reinforced concrete shear core structures. The design of the 13 storey Rutherford House is used as basis of these notes to illustrate the process in general terms.

\section{Building Description}

Rutherford House is to be located on the block formed by Lambton Quay, Bunny and Featherston Streets, Wellington. It has been designed for the Head Office of the New Zealand Electricity Department, but includes office space for the Wellington City Council Transport Department as well as associated car parking areas and shops.

The building consists of a basement, ground floor, mezzanine floor at first floor level, 12 main floors of approximately 9,000 sq.ft. gross area, plus a penthouse housing services equipment. Construction is to be of reinforced concrete throughout with the exception of the penthouse, which is structural steel framed. The structural framework and shear core are symmetrical in plan about both the longitudinal and transverse axis as shown in Fig. Bl. Foundations consist of tied footings and strip foundations bearing on preconsolidated silts and gravels in a clay matrix.

\section{General Considerations}

The building is designed to comply with the current New zealand loading code, N.Z.S.S. 1900; Chapter 8, Basic Design Loads, and P.W. $81 / 10 / 1$, Design of Public Buildings. The loadings were checked in the later stages of design by a method of dynamic analysis and were confirmed as being satisfactory.

Inspection of the relative lateral stiffnesses of the shear core and perimeter frames shows that the core resists almost all the applied lateral loads. (Later analysis shows that the core resists $90 \%$ of the applied loads at the top of the structure and $99 \%$ at the lower levels). However, the structure is analysed as a whole to determine the forces induced in the frame by shear core deformation.

The shear core is assumed fully fixed at ground floor level since the main resisting elements are about 30 times stiffer below this level. Rotations of the foundation structure under seismic loadings are neglected since no major relative displacements can occur between elements of the main structure.

\section{Idealisation of the Structure}

Since torsional effects are not significant only half the structure is considered for each of the longitudinal and transverse seismic analysis. For analysis in the longitudinal direction the idealised structure consists of a 'frame' of 4 bays, made up of columns and spandrel beams, and a 'wall' 


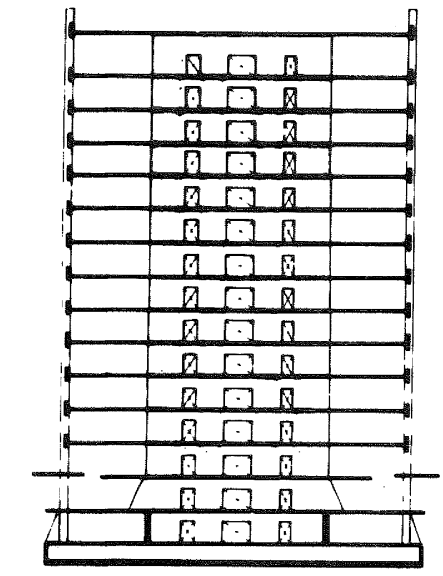

LONGITUDINAL WALL SECTION

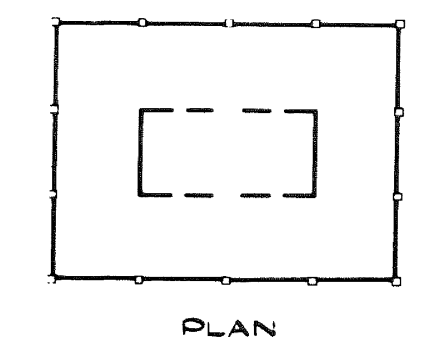

RUTHERFORD HOUSE WELLINGTON

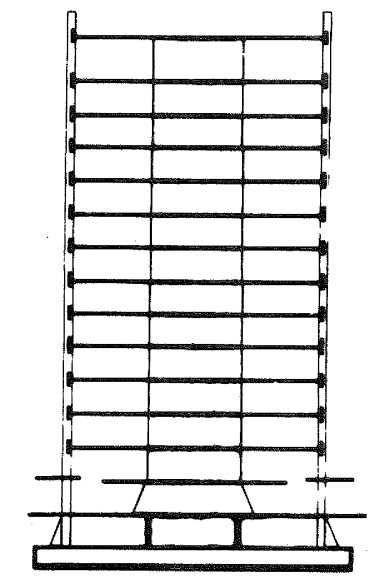

TRANSVERSE WALL SECTION

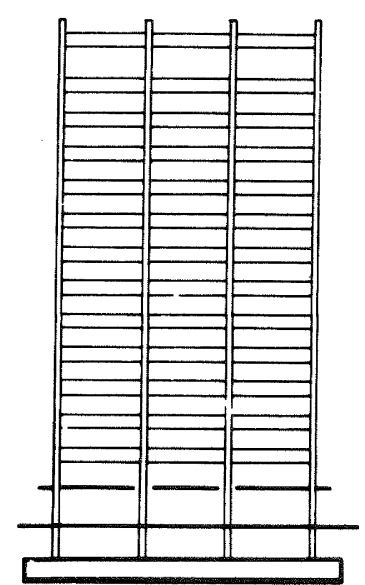

frame elevation

Fig. Bl

of 5 bays made up of columns, floor slabs, shear core piers and beams. Transverse analysis consists of a similar 'frame' section plus a broken channel section 'wall'. See Fig. B2. The whole of the shear core vertical elements are considered effective.

Elastic section properties of gross concrete sections are used throughout. Any reductions in stiffness resulting from cracked sections is assumed to occur in all members thus keeping relative stiffness values constant. Special investigation is made, however, of the reduced stiffness of the shear core coupling beams with respect to the other elements since they are subject to relatively high forces and large deformations.

A certain amount of in-joint flexibility is considered by taking members a distance equal to the member depth/4 past the face of the connecting members. See Fig. B3. Where the effective members do not meet the joint, allowance is made for a rigid zone. The effect of a 


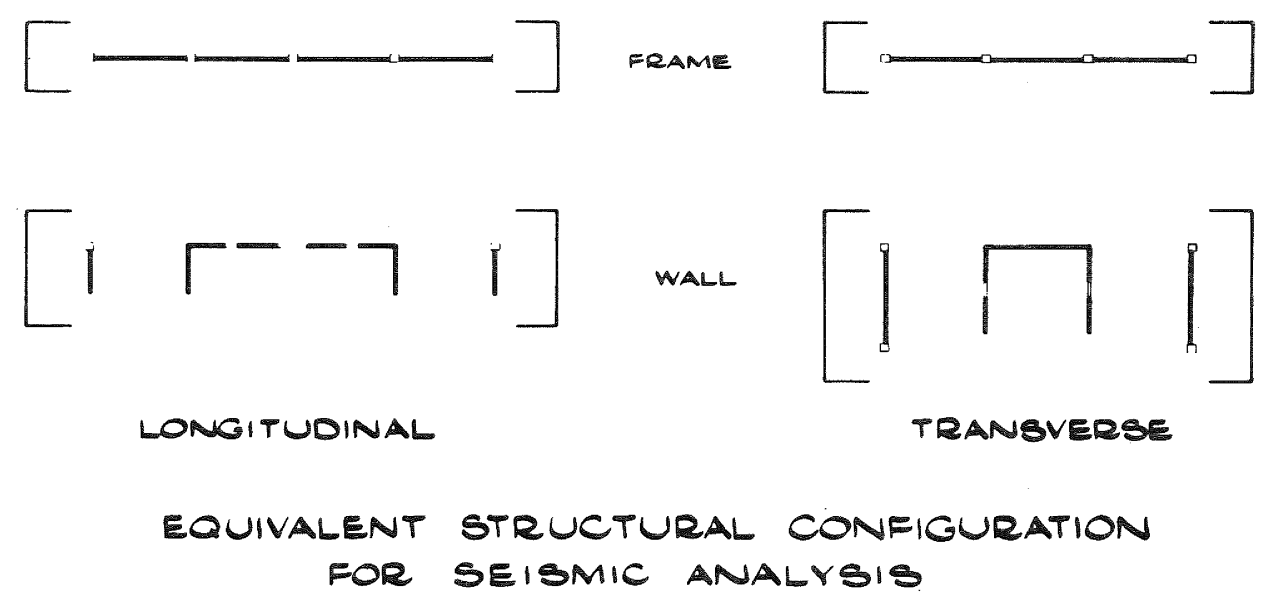

Fig. B2

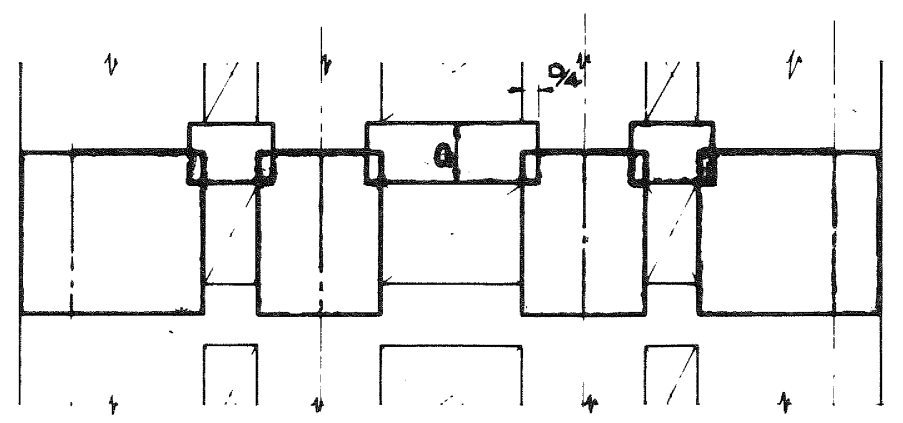

EQUIVALENT MEMBERS FOR MATHEMATICAL MODEL OF LONGITUDINAL SHEAR CORE

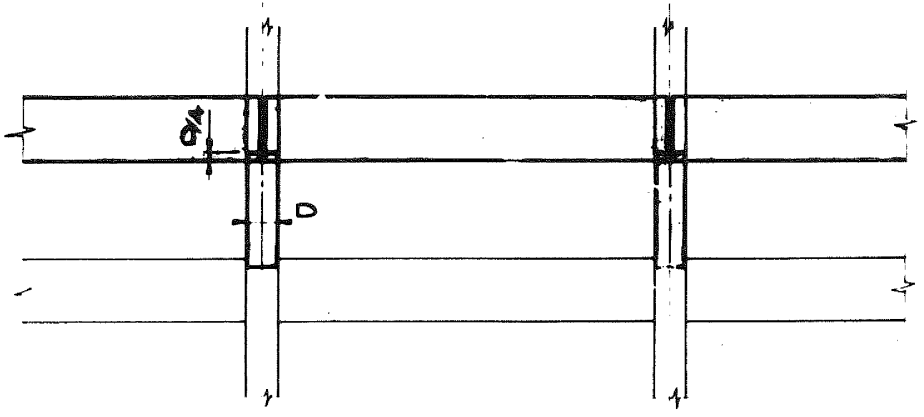

EQUiVALENT MEMBEES For MATHEMATICAL MOOEL OF FRAME COLUMNS ANO SPANDEEL BEAMS

Fig. B3 
rigid zone on the rotation at the end of a member is shown in Fig. B4. This allowance is made for columns in the 'frame' sections and for beams in the shear core sections. See Fig. B3.

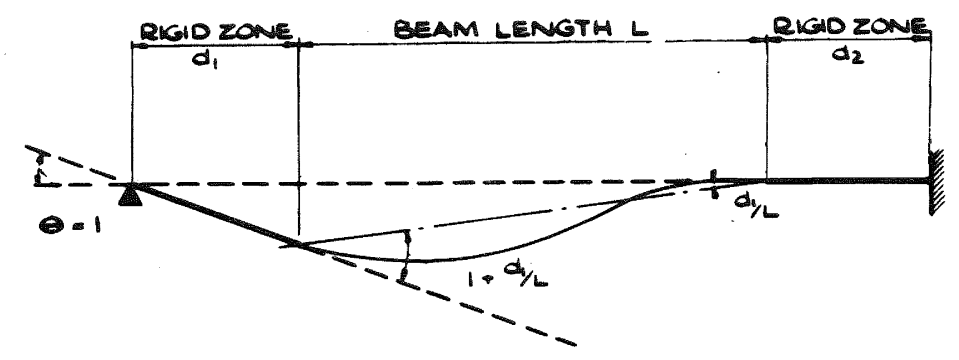

EFFECT OF RIGID ZONES

ON BEAM DEFORMATIONS

Fig. B4

The effect of shear distortions is allowed for in assessing the stiffness of deep members. For beams the stiffness and carry-over factors are adjusted according to the following expressions:-

Member Stiffness Factor $=4$ for slender prismatic members $=\frac{2 E I}{L}\left(\frac{2+B}{I+2 B}\right)$ for deep members

Member Carry-over Factor $=0.5$ for slender prismatic members $=\left(\frac{1-B}{2+B}\right)$ for deep members

Where $\mathrm{B}=\frac{6 \mathrm{EI}}{L^{2} \overline{\mathrm{A}} G}=$ shear flexibility factor.

Only symmetrical beams can be fully catered for in the present form of computer programme. Shear distortions are automatically allowed for in columns provided shear area data is given. Haunched columns at ground floor level, and variations in effective beam lengths up the shear core are considered using approximations and equivalent member properties.

\section{Computer Analysis}

Analyses were initially carried out using a computer programme originating from the University of California, and the facilities of the Commonwealth Scientific and Industrial Research Organisation Computing Bureau at Canberra through the courtesy of the Commonwealth Department of Works, Australia.

The Ministry of Works now posses this ability, and subsequent analyses, making allowances for amendments and investigating various effects, were carried out in Wellington, as were the dynamic analyses to confirm code loadings. 
A description, including basic assumptions, limitations and data required, of the computer programme used is included as Appendix A to these notes. The method of analysis is fully covered in the reference given with this description.

\section{Special Investigations}

The loadings specified in N.Z.S.S. 1900; Chapter 8 were checked using a form of dynamic analysis approach. This method has been widely published by R. Shepherd, University of Canterbury, and involves the determination of the structure lateral stiffness matrix; periods, modal shapes; equivalent Ig modal responses; appropriate earthquake response factors; back substitution of the equivalent deformed shapes through the stiffness matrix to determine the individual member forces: estimation of an envelope of effects by the root/sum/square method. The computer programme used for static load analysis is modified, to carry out these operations using basically the same data.

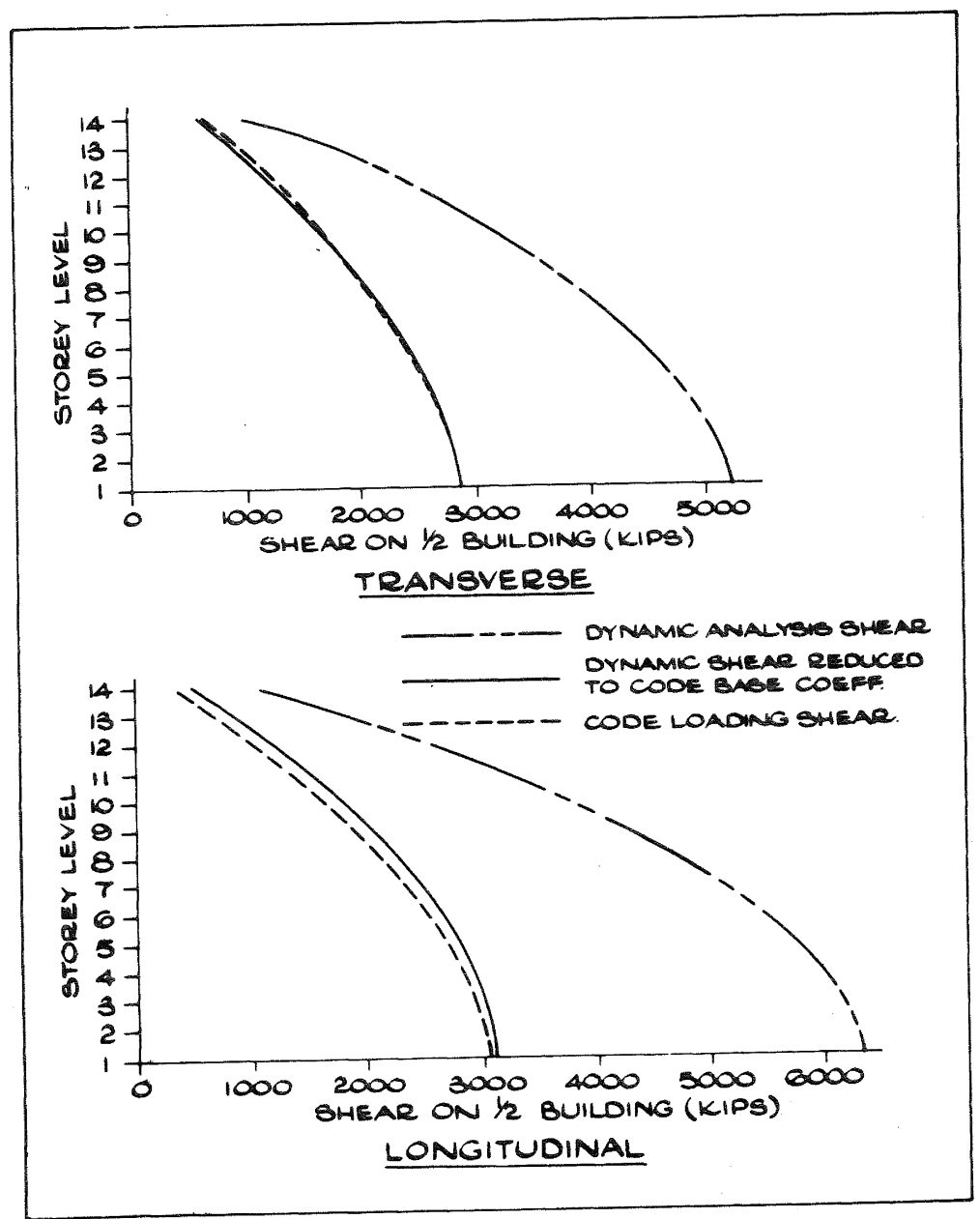

Results are compared with the specified code loading in Fig. B5 by a comparison of the applied shear force. It is interesting to note that factors of 2.03 in the longitudinal direction and and 1.85 in the sransverse direction are required to reduce the dynamic analysis base shear to that required by the code. This is substantially lower than the value of 4 given in the commentary to N.Z.S.S. 1900, Chapter 8. Furthermore the reduction factor requirement of individual elements of the shear core are of about the same order, with a maximum of 3 upper storey beams.

Fig. B5. 
The loadings given in N.Z.S.S. have been confirmed as being satisfactory, excepting that a slightly heavier load should be applied at the top level for analysis in the longitudinal direction. No reduction to code loading was used in the design.

Incremental failure was investigated by means of reducing the relative stiffness values of various members and re-analysing the structure. The critical members of the shear core are the coupling beams, and successive analyses were carried out progressively reducing their moment of intertia values down to that corresponding to the cracked transformed section at ultimate load for all beams. Allowance was made for a reduced seismic loading corresponding to the period of the more flexible structure in accordance with the values given in N.Z.S.S. 1900; Chapter 8. Taking the reduced loading into account, the envelope of effects of the reduced shear core beam stiffnesses are shown in the graphs of Fig. B6.
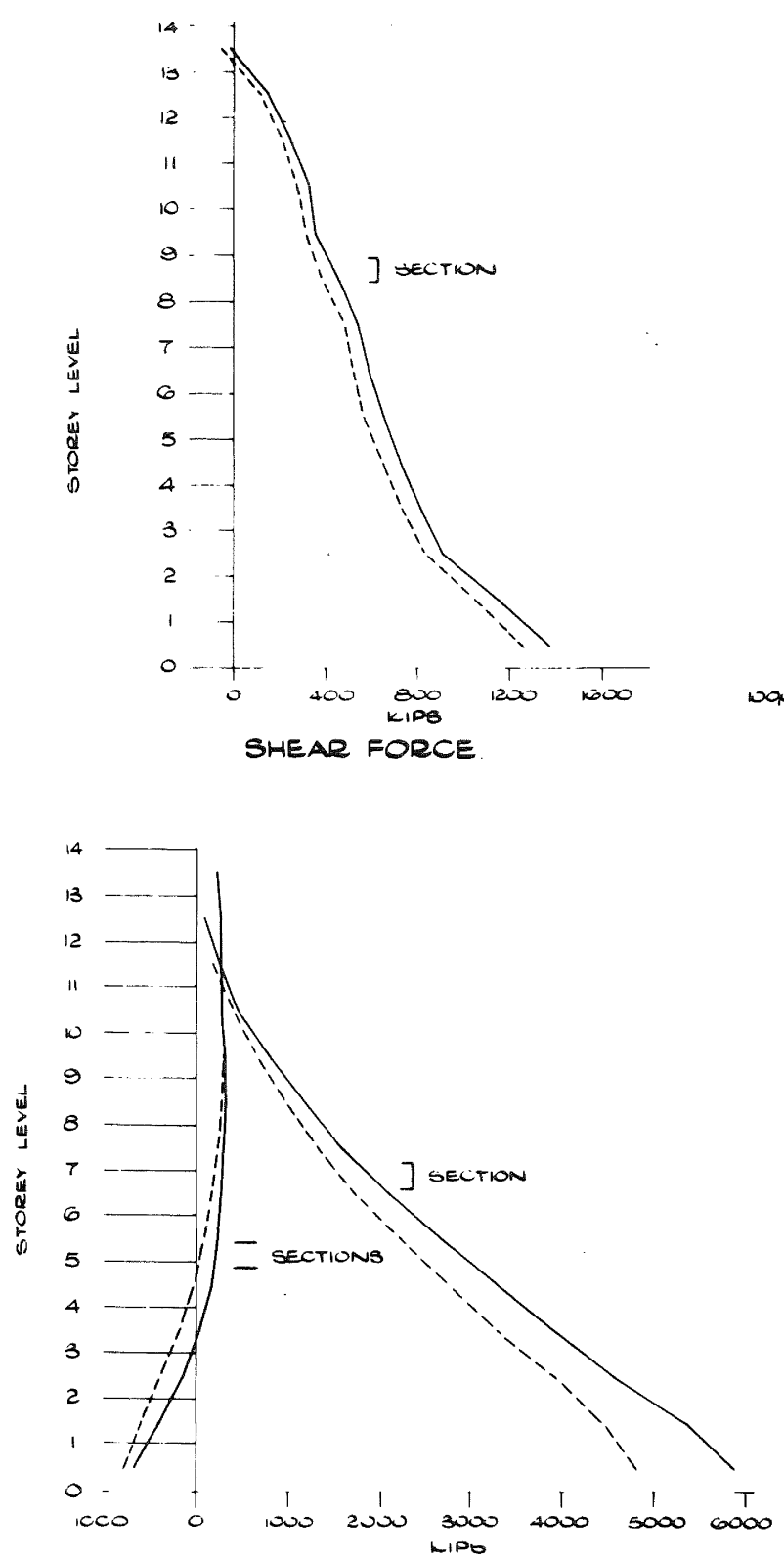

AXIAL FORCES

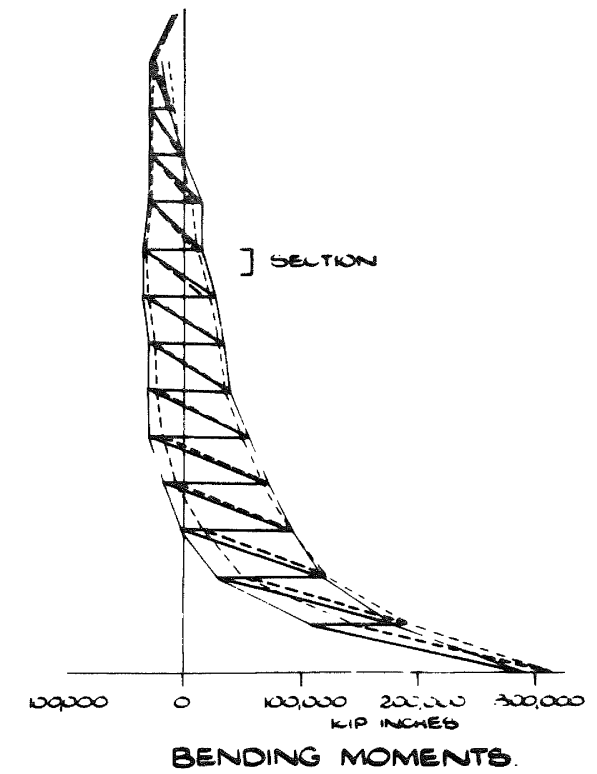

BENDING MOMENTS.

RUTHERFORO HOUSE: LONGITUDINAL SEISMIC ANALYSIS SHOWING THE EFFECTS OF REOUCED BEAM STIFFNESS USING NZSS IDOO CHAPTER 8 BASIC SEISMIC COEFFILIENTS 


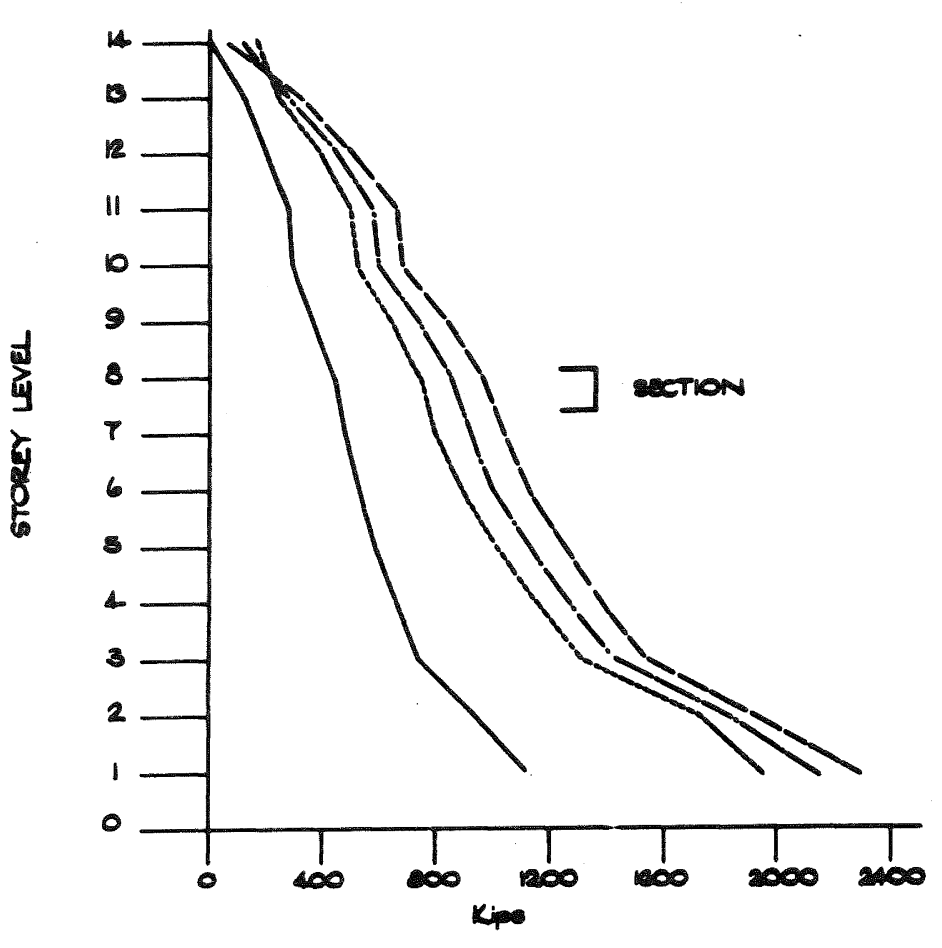

BHEAR FONCE

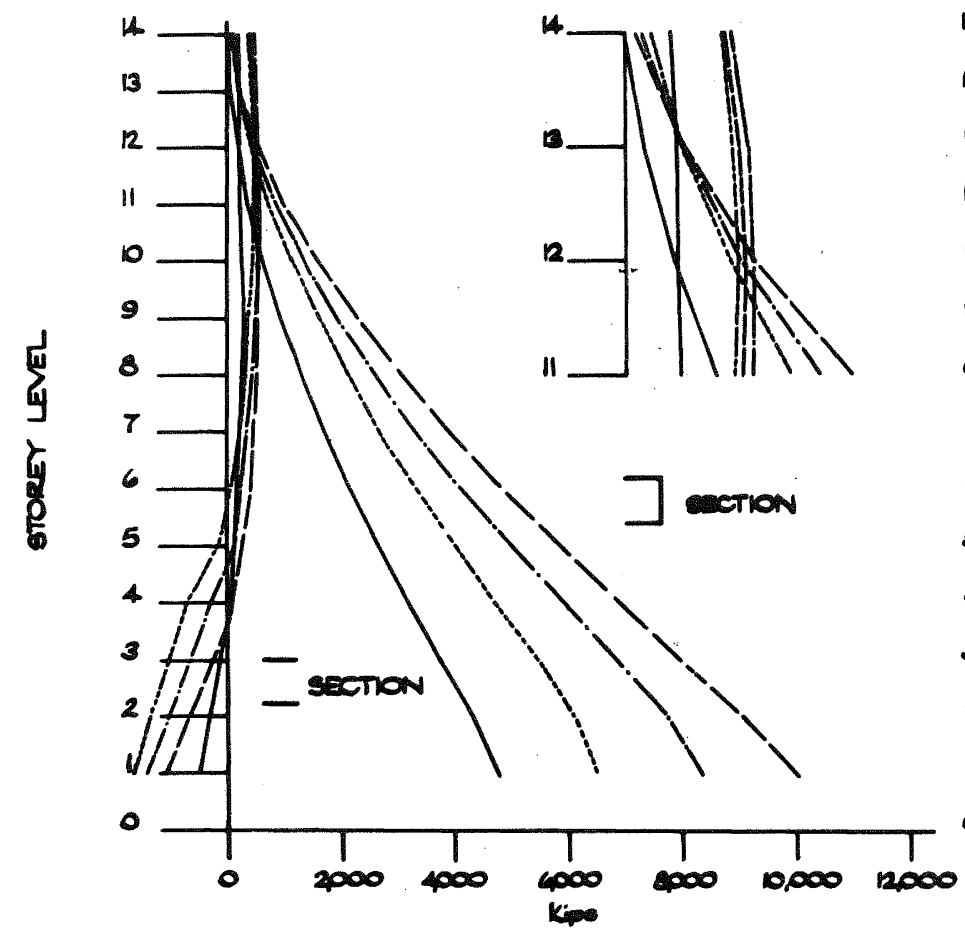

AXIAL FORCES

RUTHERFORO DOUE : LONGITUDINAL EFIEMIC ANALYSIS CHOWNG THE EREETS OF REOUCED DEAM STIFFNESS IN GHER WALL UNDER ELAOTIC OTNAMIE ANALYSIS

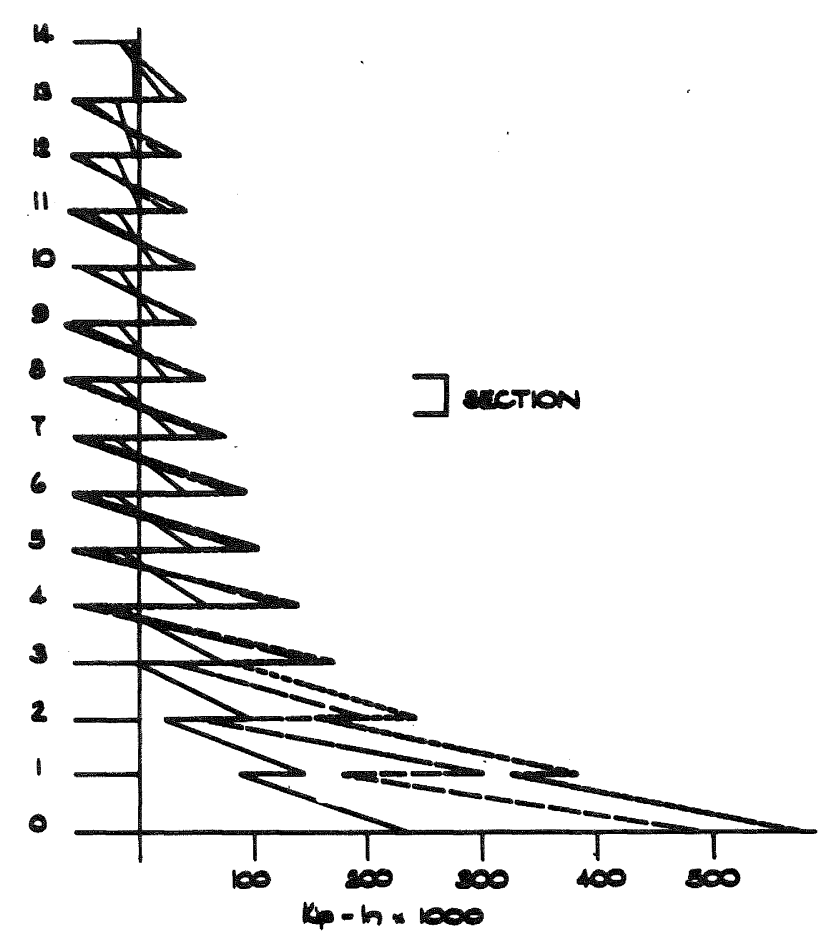

DENONG MOMENTS

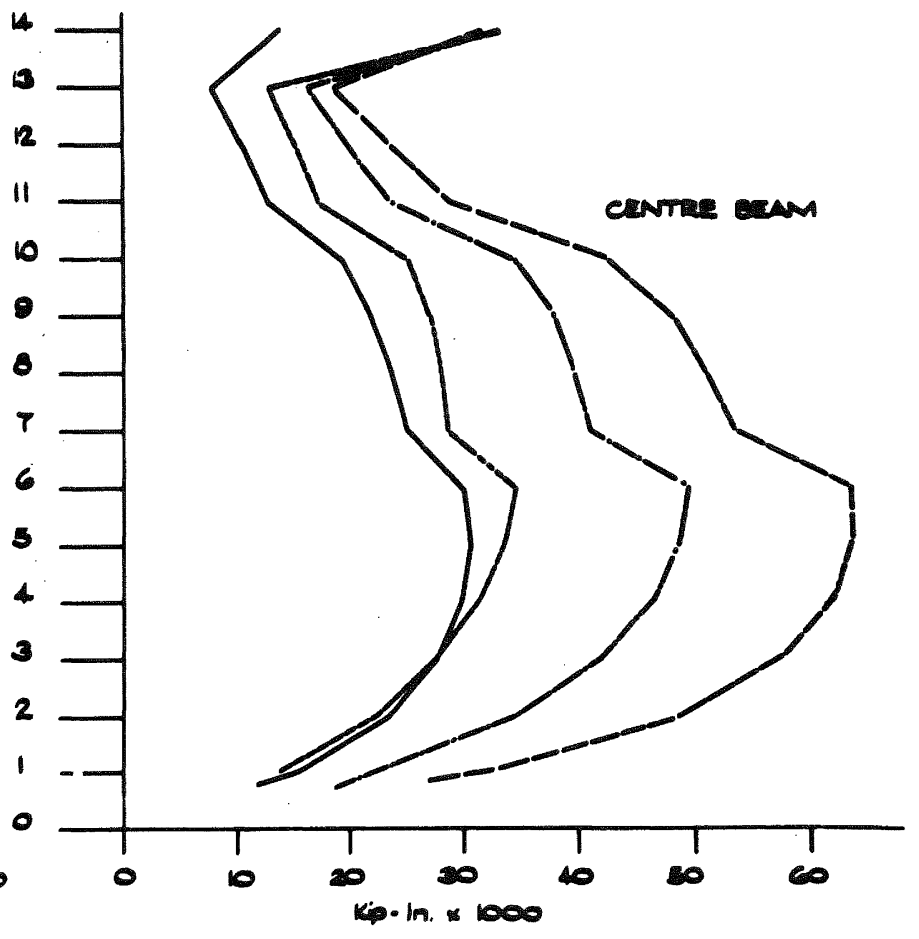

EENDINC MOMENTS

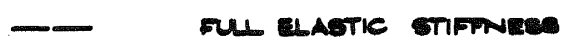

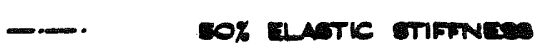

- $25 \%$ inatic onfintes cose mourina lonos 
The effect of reduced stiffness in the shear core coupling beams was also investigated through an elastic dynamic analysis, the results of which are shown in fig. B7 and B8.

\section{Design of Reinforced Concrete Shear Wall Segments}

Design is based on ultimate strength methods in accordance with A.C.I. 318-63 and P.W. 81/10/1 code of practice for the Design of Public Buildings. Only the detailed design of shear core segments subjected to bending and axial load is presented.

Determination of the state of stress in a cracked reinforced concrete section subject to axial load and bending is impractical under ultimate strength design methods since a particular combination of ultimate loading may not be possible for that section. An alternative approach is to fix one of the loading criteria, determine the position of neutral axis to satisfy that condition, and hence find the corresponding load effect. This involves a solution of equations, which are quadratic when tension governs and cubic for compression governing, and is usually carried out to sufficient accuracy by trial and error methods.

A more efficient approach is to determine a reinforcement arrangement, select successive positions of the neutral axis, determine the corresponding values of axial load and moment capacity for each position, and plot the interaction curve. This may be carried out for a range of reinforcement patterns to give a set of interaction curves as shown in Fig. B9. In many cases only a part of the interaction curves for any one section are required and are obtained by determining 3 or 4 points.

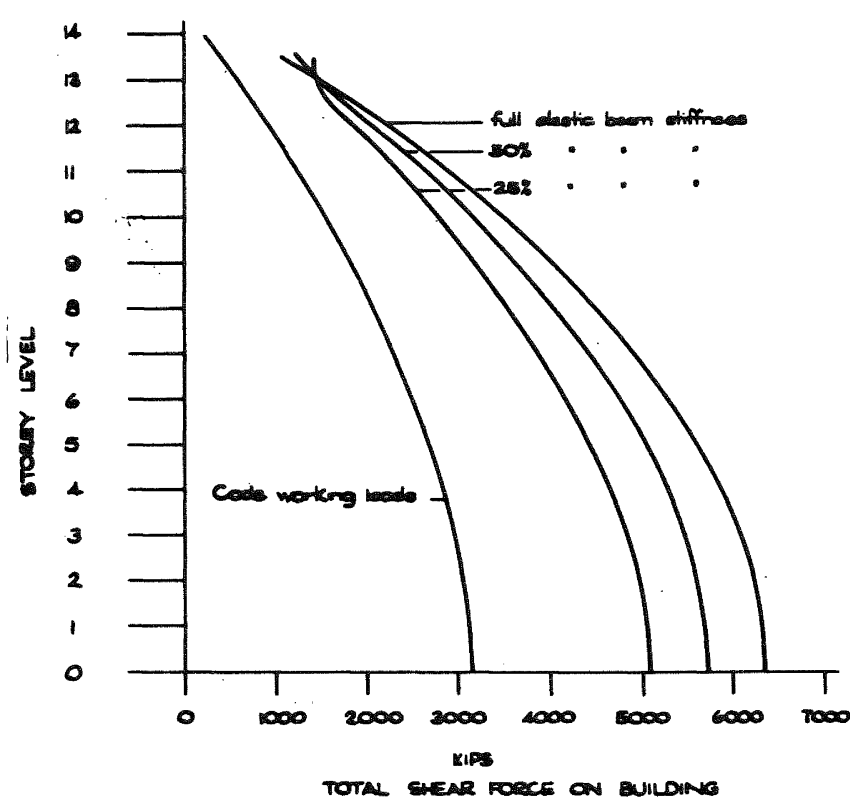

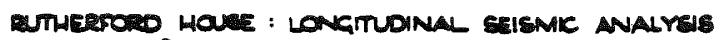

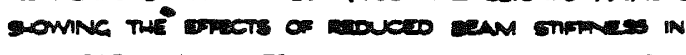

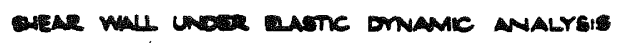

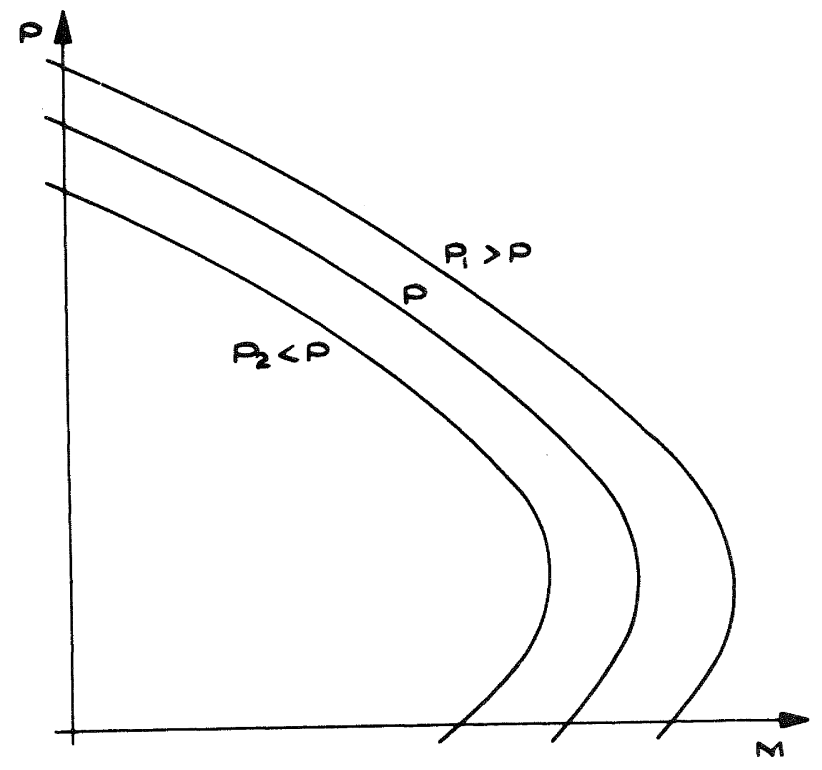

TYPICAL NTERACTION DIAGRAMB FOR VARYING REINFORCEMENT PERCENTAGE 
An example of the computation to obtain inter-action values for a section subjected to axial load and bending moment is given in Appendix $B$. Under practical conditions the accuracy given would not be required, and with practice approximations can be made which give satisfactory results.

Shear core segments are designed and reinforced on the basis of tied columns. The undercapacity factor of 0.7 is used where extensive compression areas are involved and where a local compression failure materially effects the overall capacity of the section. See Fig. BIO(a). Where only part of a segment is under compression, and the compression area can spread to adjacent parts without effecting the overall resistance of the element in event of a local failure, the use of an undercapacity value of 0.90 can be justified. See Fig. Bl0(b).

Applications of ultimate strength design methods to large members subject to small compressive (or tensile) axial loads assumes reinforcement capable of withstanding strains many times that at yield. Practical cases to date have required strains well within the minimum elongation specified for reinforcement. The effect of limiting steel strain, to say 15 times yield strain, has been examined and has shown sections to be capable of carrying the required loads under these conditions. The possibility of large strains emphasises the necessity of a ductile reinforcing steel and the attention that should be made to reinforcing details.

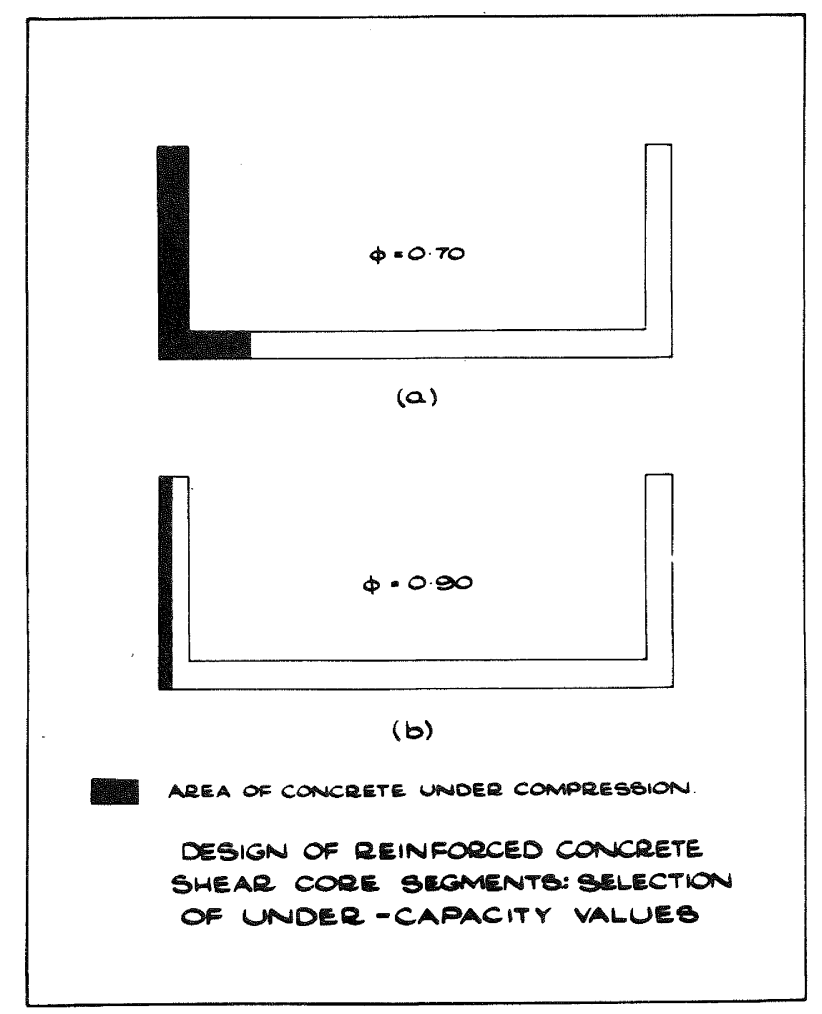

Fig. Blo. 


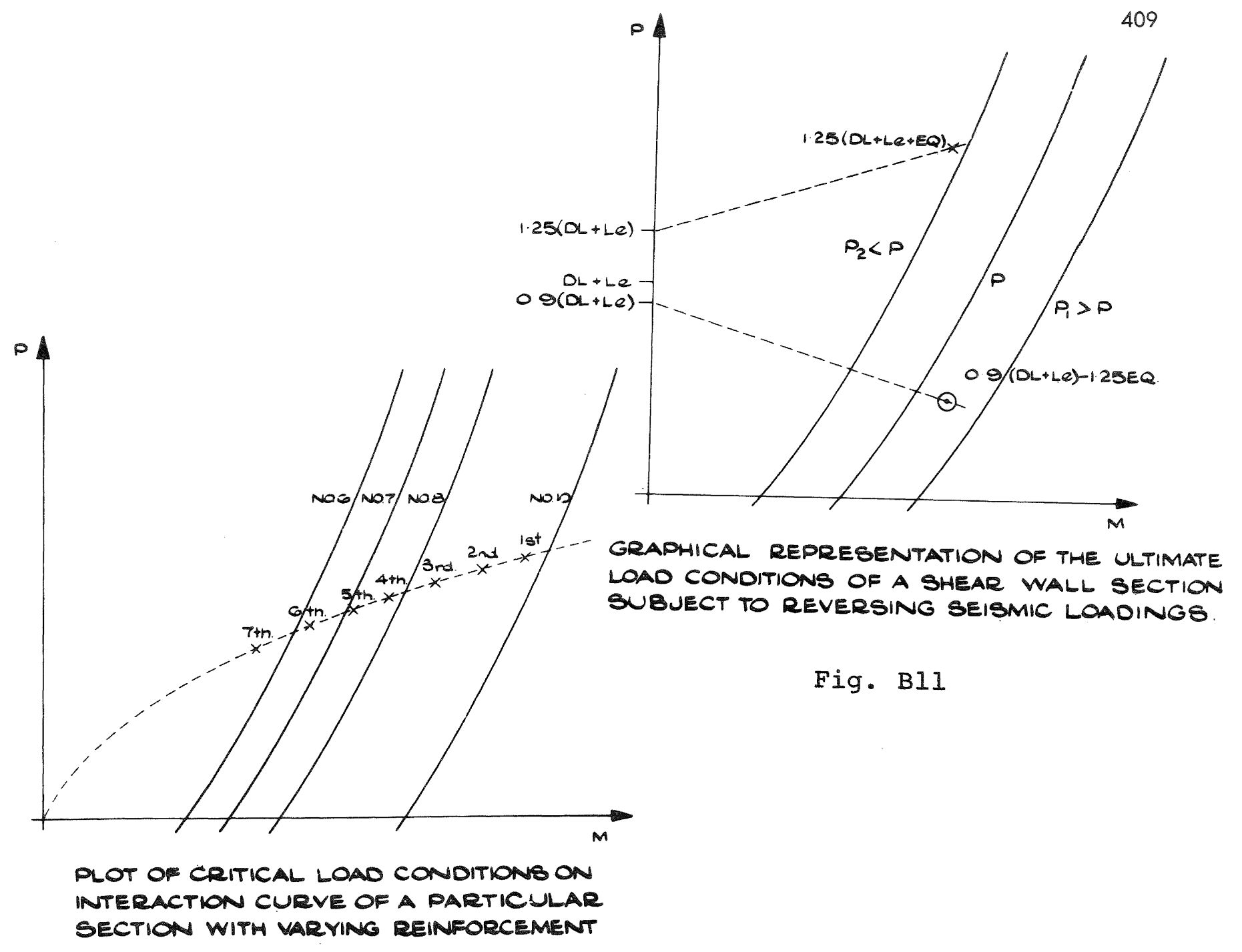

Fig.B.12

Experience to date has shown that shear cores fall into a range of loading such that the moment capacity increases with an increase in axial load. The critical load condition is shown diagrammatically in Fig. BII where the states of load in a section at points in a possible loading cycle are given. Without seismic loading the ultimate load conditions are shown as 0.9 (DL $+L e)$ or 1.25 ( $D L+L e)$. The seismic loading causes bending in the section while increasing or decreasing the axial load resulting in the ultimate load conditions 1.25 (DL + Le $+E Q$ ) or 0.9 $(\mathrm{DL}+\mathrm{Le})+1.25 \mathrm{EQ}$ as shown.

Fig. B12 illustrates a plot of critical load conditions against a set of interaction curves. From this the designer can determine the reinforcement required at various locations.

Our method of design of a shear core element for shear forces is illustrated in Fig. B13. Under reversing loading, where the member is going into the yield range, shear displacement may cause interface grinding of the concrete and destroy the interlocking effect. Hence, at any potential crack in a section, there must be sufficient reinforcement crossing it to resist the applied shear. Assessment of the potenti.l crack is subject to many variables including the axial load, position of construction joints, floor slabs, etc., and is normally taken as being a 


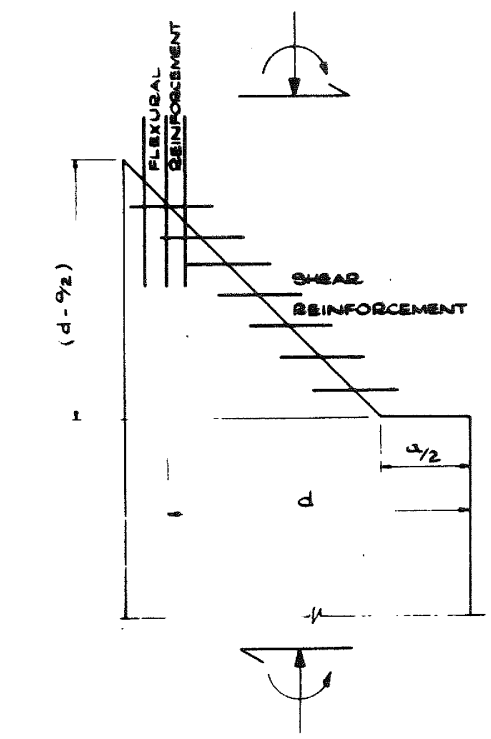

DIAGRAM OF FREE BOOY FOR DETERMINATION OF SHEAR REINFORCEMENT ANO CUT OFF OF. FL EXURAL REINFORCEMENT FOR LARGE MEMBERS

Fig.B.13.

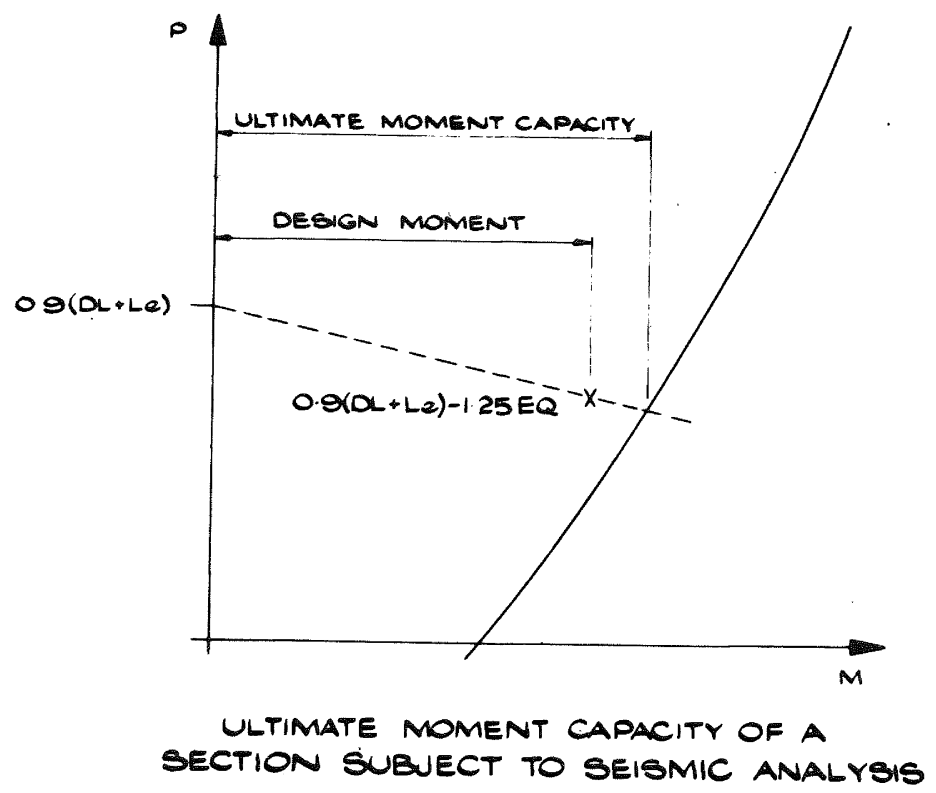

Fig.B. 14 
45 degrees originating at the centre of concrete compression. For stirrup reinforcement this is the equivalent of using the equation (in A.C.I. 318-63 notation).

$$
v_{u l t}=A_{V} \varnothing f_{Y}\left(\frac{d-\frac{a}{2}}{s}\right)
$$

For members of normal proportions $\left(d-\frac{a}{2}\right)=d$ which results in the A.C.I. equation.

To ensure that elements of a shear core act in a ductile manner, members should be designed and detailed so that they yield in flexure to ultimate before failure in shear or compression. Thus the shear resistance of any member should be greater than the moment capacity. To achieve this, design shear forces are based on the moment capacities of a member rather than the forces resulting from code loadings. In the case of the coupling beams of a shear core the design shear would be determined from the expression

$$
V_{u l t}=\frac{\text { Mu (Left) }+ \text { Mu (Right) }}{\text { Span }}
$$

where $\mathrm{Mu}$ is the ultimate capacity. In the case of pier or column elements the ultimate moment capacity is determined from the projection of the force situation on the interaction curve. Fig. Bl4. In general it is considered sufficient to shear reinforce against only the critical flexural failure.

The rate of cut-off flexural reinforcement is also determined from consideration of a potential crack formation, as shown in Fig. B13. By taking moments of the free body about the centre of concrete compression, including the applied bending moment, axial and shear forces, as well as the resistance of the shear reinforcement, the flexural reinforcement crossing the crack to obtain equilibrium conditions can be calculated. Again for members of normal proportions, these considerations result in provisions similar to those required by A.C.I. 318, or more specifically, those of N.Z.S.S. 1900; D8815.

\section{Reinforcement Details}

Reinforcement detalls often determine the thickness requirements of the elements of reinforced concrete shear-walls. In the particular case of coupled shear walls, shear stresses in the coupling beams usually govern the minimum thickness and reinforcement at the critical levels and often establishes a reinforcement pattern throughout. In reinforcing coupling beams highly stressed in shear, stirrups should enclose the flexural bars. Pier or column elements are designed on the basis of tied columns and main reinforcement must be tied against buckling and concrete confined in some areas. To assist in achieving this the vertical flexural reinforcement is enclosed by a horizontal shear reinforcement. At the junction of coupling beams and column sections, congestion can be avoided by using the beam flexural reinforcing and the column shear reinforcement in the same plane. Hence the pattern of reinforcement is set; cover to beam shear reinforcement; beam flexural reinforcement inside the shear reinforcement, column shear reinforcement in the same plane as beam flexural reinforcement, and column flexural reinforcement inside column shear reinforcement. 
Construction Contractors generally have preference for reinforcing details and the Ministry of Works are often prepared to accept alternatives which are proven to be satisfactory. However, a great deal of attention is given to details in order to obtain ease of construction and satisfactory performance.

Butt welded splices of flexural reinforcement in shear cores are favoured for heavy bars to avoid the congestion and stress raising effects of lapped splices as well as obtaining a better performance for large strains. The option is given for intermediate bar sizes to be welded or lapped. Investigation and tests ate being carried out on a method of pressure-gas welding of bars. (See Bulletin Vol.2. No.3 - Ed.)

For ease of construction, placing, and tolerance, shear reinforcement stirrups in the column segments are detailed in the form of a U (shop formed) which is then closed by field welding the legs through a steel plate. This provides anchorage and assists in confinement of concrete. Welded closed stirrups are used in the beam segments.

In detailing to comply with the tied column basic design basis, ties are provided across the wall linking the outer layers of shear reinforcement. These links are provided at 18 inch centres along each bar and are staggered on alternate bars. For shear reinforcement at 9 inch spacing this is equivalent to a tie per $11 / 8 \mathrm{sq}$. feet of wall space. Use is made of the shear reinforcement to prevent buckling of the flexural reinforcement between ties.

Similar ties or links between the shear reinforcement are used in regions where confinement of concrete is required. Both horizontal and vertical reinforcement may be considered effective in confining concrete.

Typical reinforcement details used for Rutherford House are shown in Fig. B15.

\section{Acknowledgements}

The writers wish to thank P. L. Laing, Commissioner of Works, for permission to present these notes.

The senior author is indebted to Dr. B. Falconer for his helpful suggestions with regard to energy dissipation factors and to $\mathrm{Mr}$ G. $\mathrm{H}$. F. McKenzie for shear wall ductility.

The junior author wishes to thank T. Pauley, R. Shepherd and R. Park of the University of Canterbury for their interest and advice, and $W$. J. Page, R. L. Williams and others of the structural design office for their contributions.

(The paper is based on material first presented by the authors in a seminar on Seismic Problems in Structural Engineering held at the University of Canterbury in May 1968.- Edd 


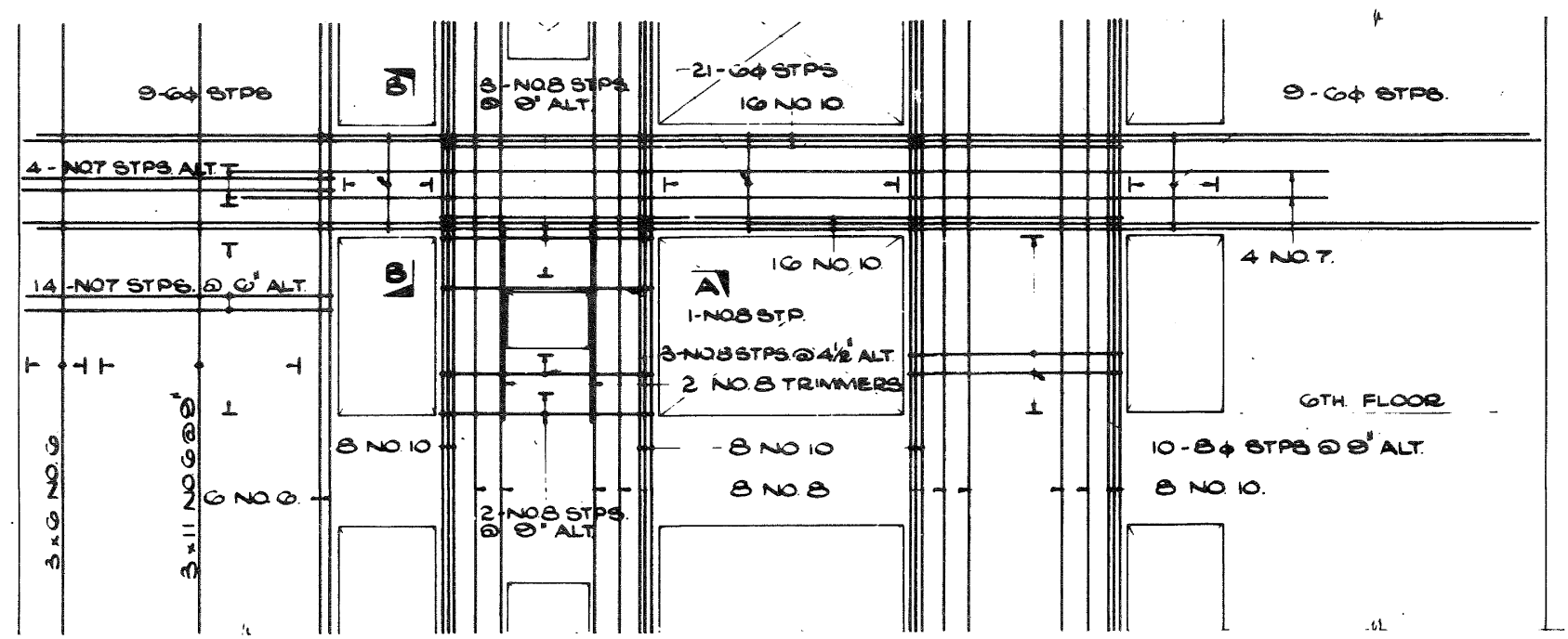

SHEAR CORE

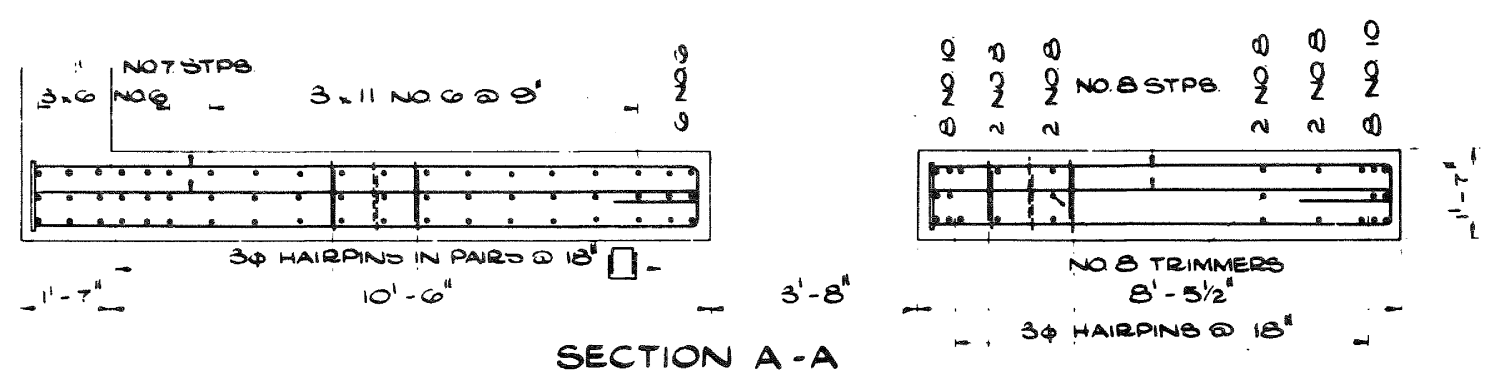

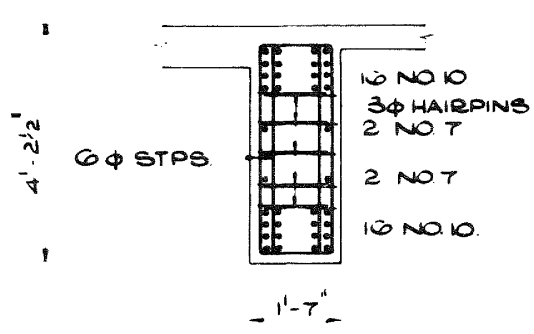

SECTION B-B

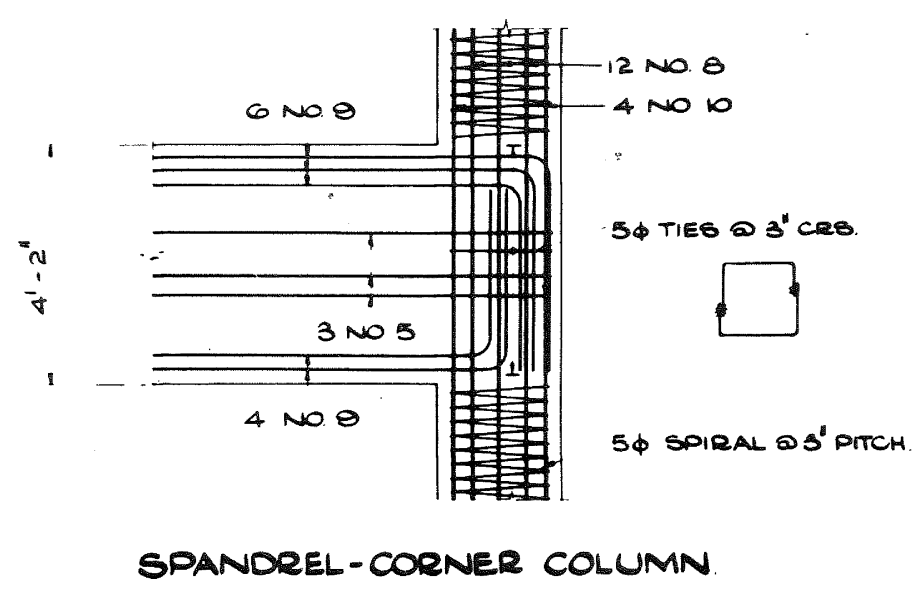

RUTHERFORD HOUSE

TYPICAL REINFORCEMENT DETAILS 


\section{Appendix A}

Computer Programme - Calfram

Static Load Analysis of Rectangular Frame Structures

Purpose

To determine the member forces (and deformed shape) in multistorey buildings made up of rectangular frames subject to vertical girder loads and/or lateral storey loads. The building frequency may also be determined.

Method

Reference should be made to 'Structural Analysis of Multistorey Buildings', Ray W. Clough, Ian P. King and Edward L. Wilson, Journal of the Structural Division, Proceedings of the American Society of Civil Engineers, June, 1964.

Assumptions and Limitations

Restrictions - The programme is restricted to structures having not more than 25 stories. Each frame must not have more than 20 column lines. There is no limit on the total number of frames in the structure. No more than three load conditions may be considered in one programme run.

Regular Rectangular Building Frame - The programme is only suitable for buildings laid out in a rectangular pattern in elevation or plan. Storey heights may vary arbitrarily, as may bay widths in each direction, but it is assumed that the complete structure is made up of sets of parallel frames acting together. Columns are assumed to extend continuously from base to top and girders from side to side. All members are assumed to be connected rigidly at the joints.

Minor variations in regularity resulting from omission of members at arbitrary locations may be accommodated by the device of assuming zero (or relatively very small) stiffness properties for the omitted members. (Similarly irregular structures may be built up to a rectangular pattern with this device). The programme treats omitted columns exactly, but only approximates the omitted girders because axial deformations along girder lines are not permitted.

Rigid Floor Diaphragms - the floor diaphragms are assumed rigid in their own plane (but have no stiffness normal to this plane), and also the loading is such, and the resistance of the structure to loading is such, that it produces no rotations of the diaphragms in their plane. Thus each floor level is constrained to translate without rotation, and each parallel frame is subjected to the same displacement at any given floor level.

Shear Walls - Shear walls may be incorporated into any of the frames. In general it is assumed that each wall is of uniform width over the entire height of the building, but its stiffness may vary with height. Shear wall arrangements in the various parallel frames may be specified arbitrarily but the assumption that the building deflects without twisting is consistent only with a reasonably symmetric distribution of stiffness. 
Axial and Shear Deformations - Axial deformation of the columns and shear walls are considered in the analysis, but girder axial deformations are neglected (as required by the rigid floor diaphragm). Shear deformations may be considered in the columns, shear walls and girders, and flexural deformations are considered, of course, in all members.

\section{Input Data}

Units - Units used must be consistent throughout the problem. Care is required with units of the Modulus of Elasticity and Mass.

Punched Cards - The following sequence of punched cards numerically defined the structure to be analysed:

\section{General data associated with complete building}

(a) TITLE CARD (72H)

Columns 1 to 72 contain information to be printed with output, e.g. Full Job name.

(b) CONTROL CARD (3I4)

$$
\begin{array}{lll}
\text { Columns } & 1-4 & \text { number of stories } \\
& 5-8 & \text { number of different frames } \\
& 9-12 & \text { number of load conditions }
\end{array}
$$

(c) LOAD MULTIPLIER CARD (3F10.2):

$$
\text { Columns } \begin{array}{r}
1-10 \text { vertical load multiplier - load case } 1 \\
11-20 \text { vertical load multiplier - load case } 2 \\
21-30 \text { vertical load multiplier - load case } 3
\end{array}
$$

The vertical loads, given on the girder cards, are modified by the vertical load multipliers within the computer programme. If, for a particular load case, the vertical load is to be omitted the load multiplier will be zero.

(d) STORY CARDS = One card per story, entered in sequence from top to bottom (1A10, 5F10.2):

$$
\text { Columns } \begin{aligned}
5-10 & \text { story identification } \\
11-20 & \text { story height } \\
21-30 & \text { lateral load - load case } 1 \\
31-40 & \text { lateral load - load case } 2 \\
41-50 & \text { lateral load - load case } 3 \\
51-60 & \text { story mass }
\end{aligned}
$$

If any one of the story masses is zero the frequencies and mode shapes will not be computed. Take care with units of mass, i.e., value of $g$ in foot or inch units must be consistent with other data. 


\section{Frame data-One set of data per frame}

(a) FRAME TITLE CARD (72H):

Columns 1 to 72 contain information to be printed with computer output associated with specific frame. It is advantageous to include the units in this information, e.g. kip/feet.

(b) FRAME CONTROI CARD (2I4, 1F12.0):

$$
\begin{array}{lll}
\text { Columns } & 1-4 & \text { number of frames of this type } \\
& 5-8 & \text { number of bays in frame } \\
& 9-20 \text { modulus of elasticity of all elements } \\
\text { in frame. }
\end{array}
$$

(c) BAY WIDTHS* (7F10.2):

Bay widths, from left to right, are punched in above format.

(d) COLUMN WIDTHS* (7F10.2):

Column widths, from left to right, are punched in above format. only necessary for columns or walls with larger width/storey height ratios.

\section{(e) GIRDER CARDS*}

One card per girder, entered from top to bottom, from left to right (7F10.2):

$$
\begin{aligned}
& \text { Columns } 1-10 \text { moment of inertia at mid-span } \\
& \text { 11-20 stiffness factor-equals } 4 \text { for prismatic girder } \\
& 21-30 \text { carry-over factor - equals .5 for prismatic } \\
& \text { girder } \\
& \text { 41-40 fixed-end-moment at left end of girder } \\
& 51-60 \text { vixed-end-moment at right end of girder } \\
& 61-70 \text { vertical reaction at left end of girder } \\
&
\end{aligned}
$$

All moments and reactions are positive for a downward load on the girder.

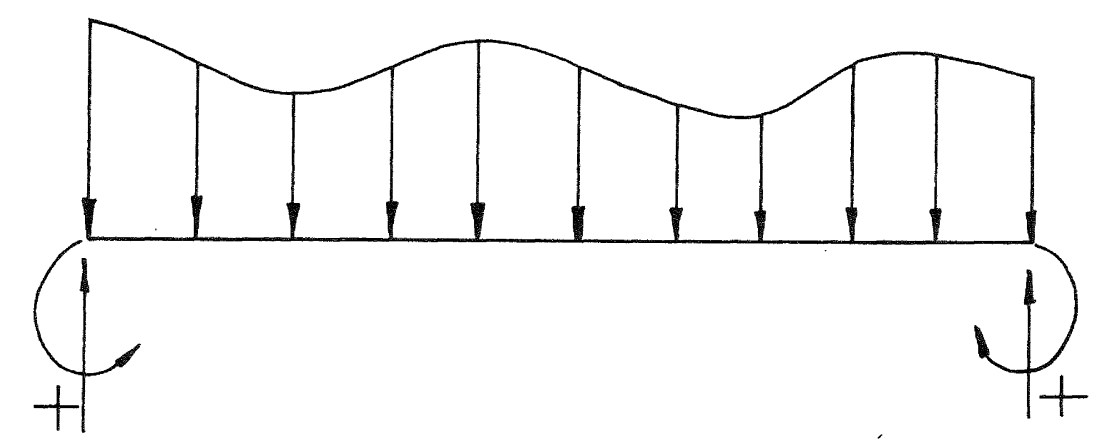

*These cards must be omitted for single shear wall - zero bays. 
(f) COLUMN CARDS - one card per column, entered in sequence from top to bottom, from left to right (3F 10.2):

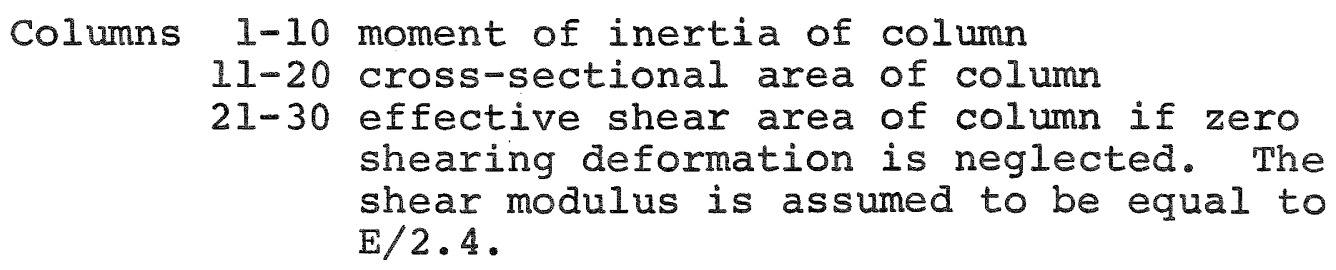

More than one problem may be analysed in one computer run simply by putting in complete sets of data in sequence.

Last Data Card - The last data card must have an integer punched in columns $73-80$.

Acknowledgement

The CALFRAM programme has been made available to the Ministry of Works through the courtesy of Professor Ray W. Clough, Professor of Civil Engineering, University of California, Berkeley, California, U.S.A. The original programme name FRMSTC has been changed to CALFRAM in recognition of its origin. 


\section{Appendix B}

Calculation of Ultimate Strength Interaction Values for a Reinforced concrete Section Subject to Axial Load and Bending

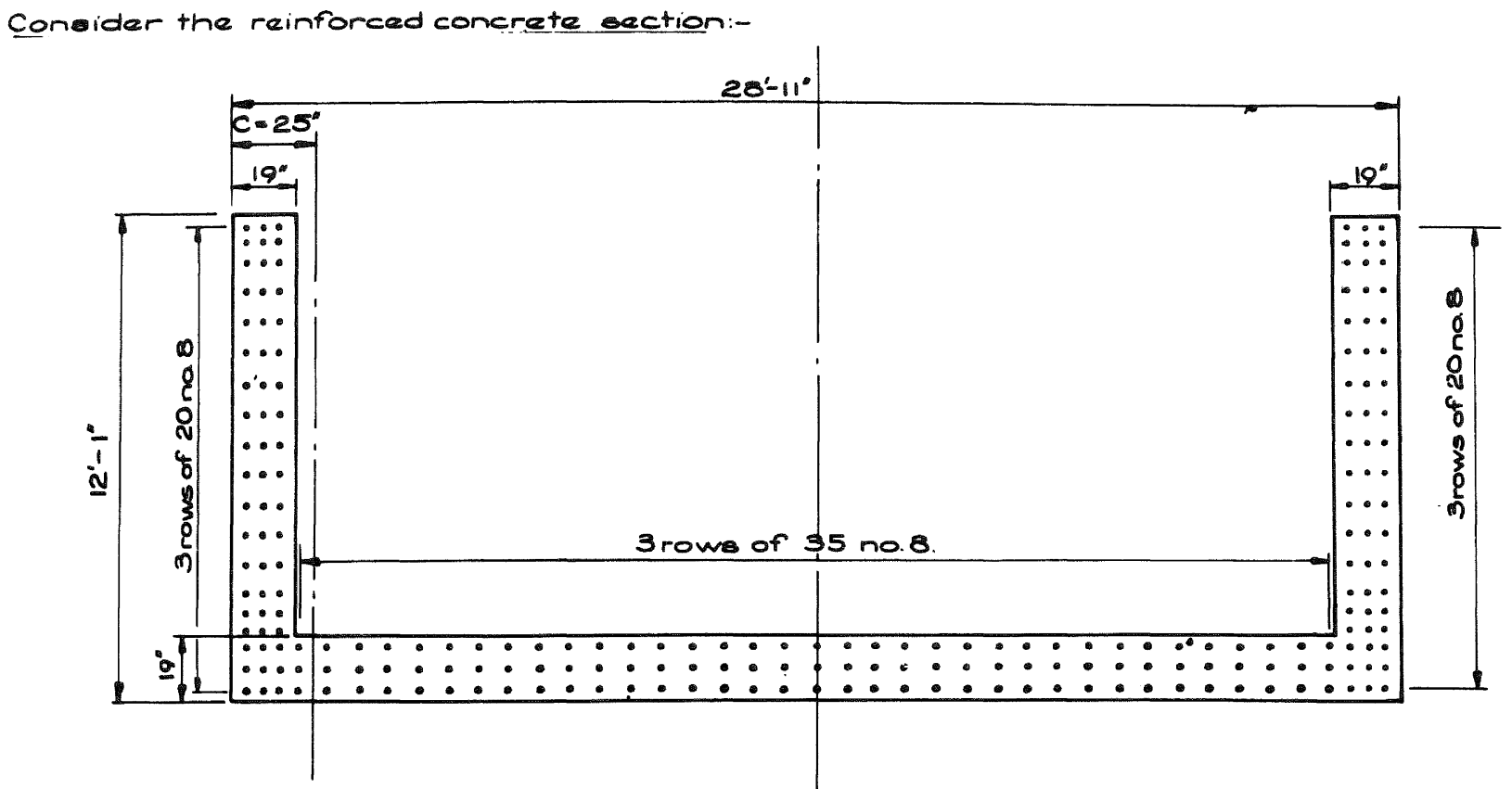

Using A.C.I notation and taking a pasition of neutral axis with C-25 (as shown above) and a maximum concrete strain of 0.003 , the strain diegram is:-

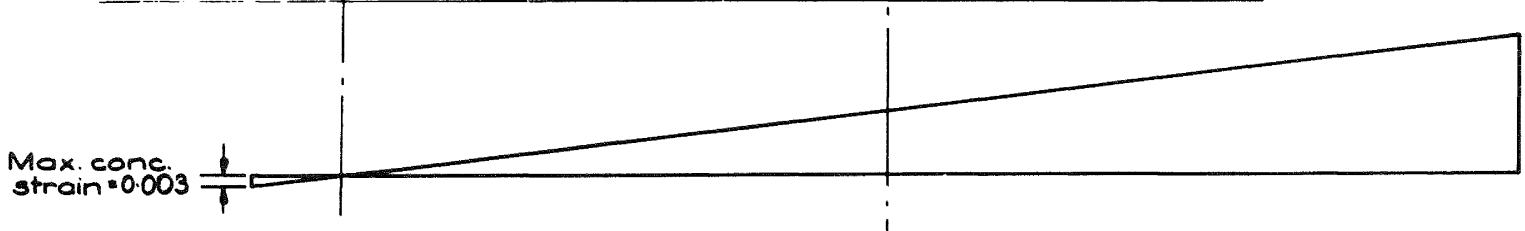

The equivalent concrete ultimate stress block, allowing an undercapacity factor $\phi=0.70$ (os for tied columne) and a concrete crushing strength $f c^{\prime}=4000$ pai.s is :-
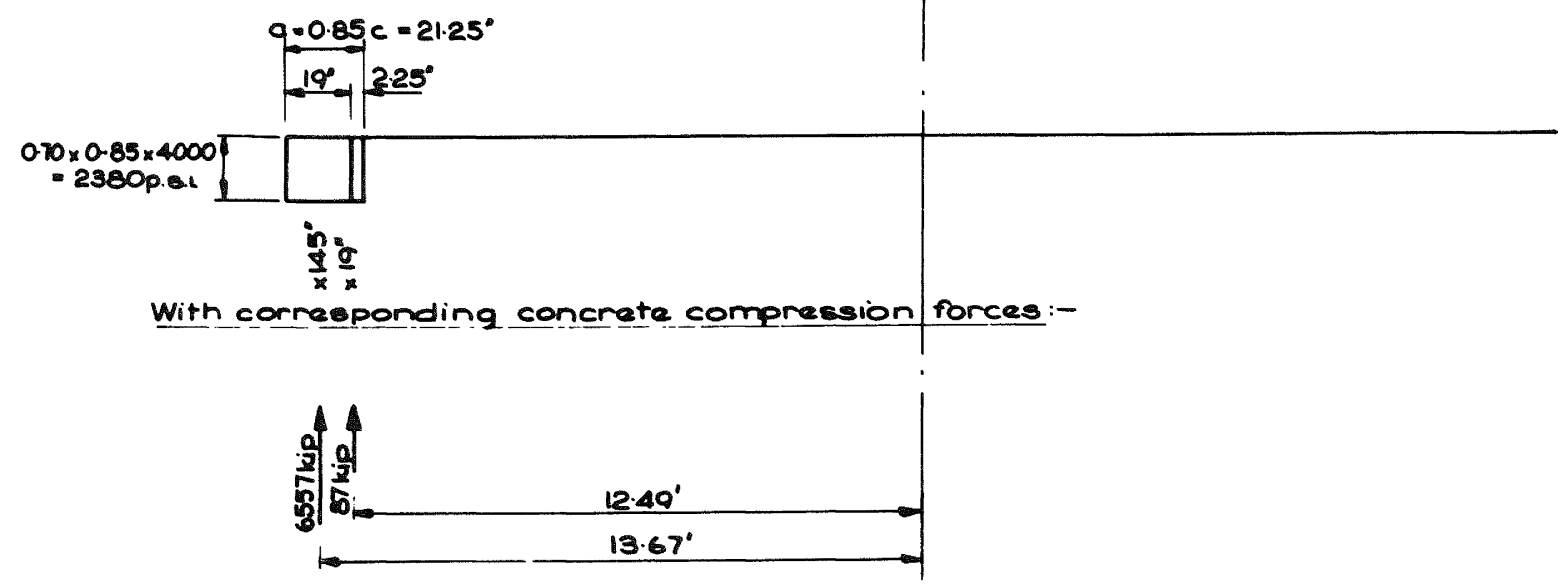
cont 'd.

Distance from the neutral axis for reinforcement to reach yield atrain $\frac{000155}{0.003} \times \frac{25}{-12.93^{\circ}}$ hence, reinforcement stress pattern is:-

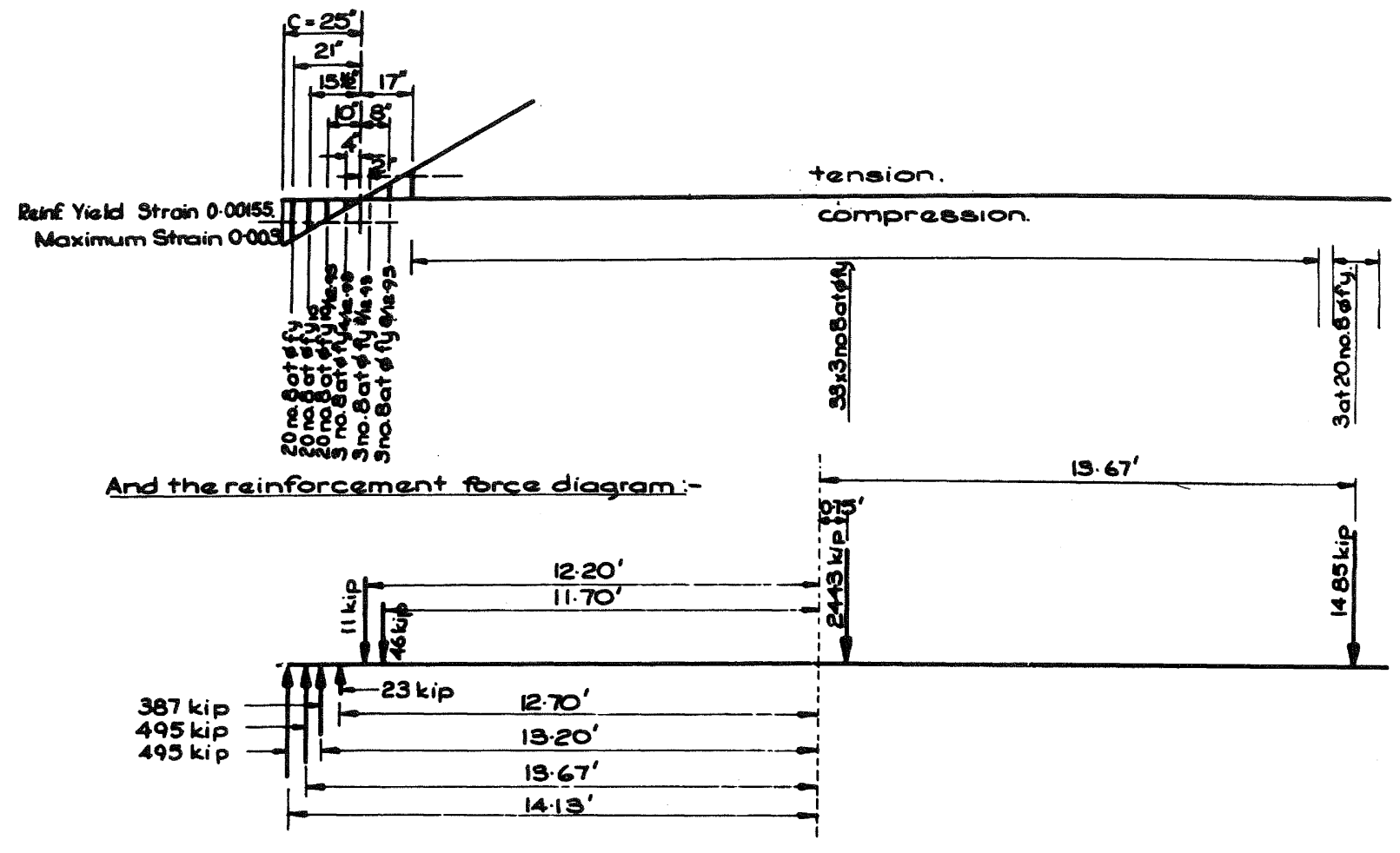

Summation of the vertical forces gives :-

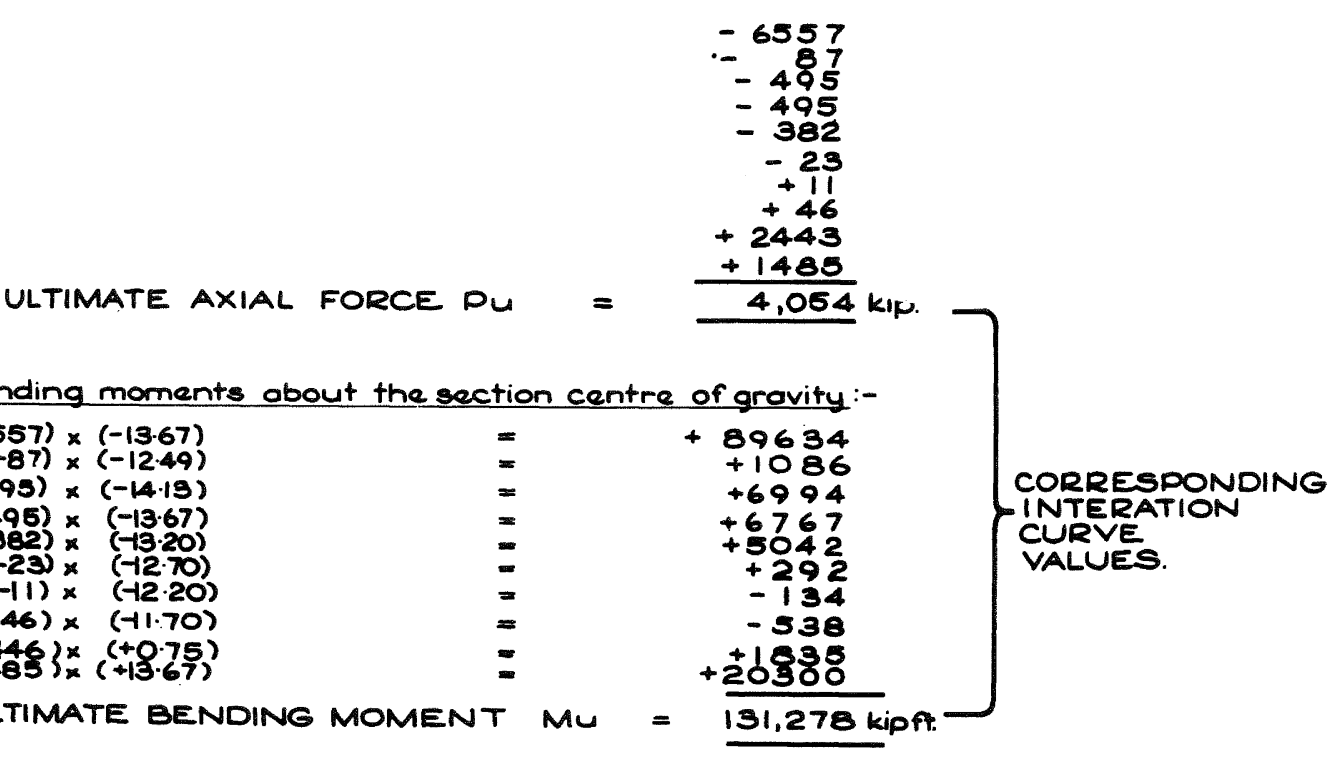

